\title{
ANOMALIAS AEROGAMAESPECTROMÉTRICAS (K, eU e eTh) DA QUADRÍCULA DE ARARAS (SP) E SUAS RELAÇÕES COM PROCESSOS PEDOGENÉTICOS E FERTILIZANTES FOSFATADOS
}

\author{
Jocelyn Lopes de Souza ${ }^{1}$ e Francisco José Fonseca Ferreira ${ }^{2}$ \\ Recebido em 21 junho, 2005 / Aceito em 25 outubro, 2005 \\ Received on June 21, 2005 / Accepted on October 25, 2005
}

\begin{abstract}
Radionuclides are present in the raw materials utilized in the manufacturing of some fertilizers and, consequently, the redistribution of uranium, thorium and potassium by agricultural activities may lead to the contamination of intensively fertilized soils. Airborne gamma-ray data on $\mathrm{K}$, eU and eTh have shown the coincidence of aerogammaspectrometric anomalies and diabase sills in the Araras region (SP). This area is situated between the coordinates latitude $22^{\circ} 00^{\prime} / 22^{\circ} 30^{\prime}$ south and longitude $47^{\circ} 00^{\prime}$ and $47^{\circ} 30^{\prime}$ west. As the contents of radionuclides in basic rocks are low and aerial gamma-ray surveys reveal gamma radiation from the $30 \mathrm{~cm}$ of the soil profile (coinciding with topsoil), interest has been raised to investigate which soils are included in the anomalies reported, as well as what sort of agricultural activity is carried out, in order to attest whether the source of radioactivity originated from the chemical fertilizers applied, thus establishing the main purpose of the present research. Integration by GIS has revealed that (i) eU and eTh anomalies occur on Latossolos Roxos massively fertilized with phosphates, on the level and elevated parts of the terrain; (ii) high levels of uranium are associated with clay particle size in regoliths developed on diabase sills; (iii) potassium and thorium anomalies follow Quaternary alluviums which extend along the banks of the Moji river, the occurrence of anomalous K accounting for the presence of feldspars in the included soils, and the occurrence of eTh related to local fertilization and to the transport of clays and iron oxides from the uppermost parts of the terrain, where the Latossolos Roxos under sugarcane are located. Radiochemical analyses of $\mathrm{U}$ and $\mathrm{Th}$ in fertilizers were in agreement with the literature, and it has been observed the influence of the geological genesis of the source of the raw material utilized in the production of the fertilizer, as well as the increase in uranium concentrations along with the $\mathrm{P}_{2} \mathrm{O}_{5}$ content. Ground gamma-ray spectrometric measurements have shown good correlation with the airborne gamma-ray detections. In conjunction with magnetic susceptibility ( $k$ ) readings have shown that uranium and thorium tend to concentrate in soils originated from the weathering of basic rocks, more developed, of clay texture, and predominance iron oxides. The retention higher than the ones found in diabase quarry.
\end{abstract}

Keywords: Soils contamination, Uranium, Airborne gamma ray, Fertilizers, GIS.

RESUMO. Radionuclídeos estão presentes nas matérias-primas utilizadas para a fabricação de alguns fertilizantes e, conseqüentemente, a redistribuição de urânio, tório e potássio pela atividade agrícola pode levar a contaminação dos solos intensivamente fertilizados. Dados aerogamaespectrométricos de K, eU e eTh mostraram, na Quadrícula de Araras (SP), a coincidência entre valores radiométricos anômalos e sills de diabásio. Esta área está localizada no estado de São Paulo, situada entre as coordenadas $22^{\circ} 00^{\prime} / 22^{\circ} 30^{\prime}$ de latitude sul e $47^{\circ} 00^{\prime}$ e $47^{\circ} 30^{\prime}$ de longitude oeste. 0 processamento e a integração dos dados de geologia, de solos, de formações superficiais, de drenagem, topográficos, de sensoriamento remoto e geofísicos, em ambiente de Sistemas de Informaçoões Geográficas (SIG), através das geotecnologias, revelaram que: (i) as anomalias de eU e eTh ocorrem sobre Latossolos Roxos massivamente fertilizados com fosfatos, nas porções planas e elevadas do terreno; (ii) os níveis elevados de urânio estão associados a granulometria argilosa em regolitos sobre soleiras diabásicas; (iii) anomalias de potássio e tório acompanham os aluviões do Quaternário que percorrem as margens do Rio Moji, atribuindo-se às ocorrências de K anômalo a presença de feldspatos nos solos inseridos, e a ocorrência de eTh associada à fertilização local e ao transporte por argilas e óxidos de ferro provenientes das porções mais elevadas do terreno, onde situam-se os Latossolos Roxos sob a cultura de cana-de-açúcar. Das análises radioquímicas de U e Th em fertilizantes, observou-se a influência da origem geológica da fonte da matéria-prima utilizada para 0 seu fabrico, bem como 0 aumento nas concentrações de urânio com 0 teor de $\mathrm{P}_{2} \mathrm{O}_{5}$ do fertilizante. Medidas gamaespectrométricas terrestres mostraram boas relações com as deteç̧ões aerogamaespectrométricas. As informações gamaespectrométricas aliadas a detecções de susceptibilidade magnética (k) mostraram que 0 urânio e o tório tendem a se concentrar em solos oriundos do intemperismo de rochas básicas, mais desenvolvidos, argilosos e com $\mathbf{k}$ elevados. A retenção de urânio e tório em solos argilosos, aliada a informações de topografia, denotaram contagens gamaespectrométricas destes radionuclídeos maiores do que as encontradas na rocha fonte (sills de diabásio).

Palavras-chave: Contaminação de Solos, Urânio, Aerogamaespectrometria, Fertilizantes, SIG.

${ }_{1}^{1}$ Rua Gerson da Graça, 94 casa 8, Bairro Seminário, 80740-690 Curitiba, PR. Tel: (41) 9916-8886 ou (41) 3361-3132 -E-mail: jocelyn_informatica@yahoo.com.br ou jocelyn.souza@utp.br

2Departamento de Geologia/UFPR/LPGA, Centro Politécnico, Jardim das Américas, Caixa Postal 19045, 81531-980 Curitiba, PR. E-mail: francisco.ferreira@ufpr.br 


\section{INTRODUÇ̃̃̃O}

Fertilizantes químicos são amplamente utilizados em regiões tropicais, especialmente em áreas de grandes culturas, como soja e trigo, consideradas de abastecimento externo. Geralmente radionuclídeos estão presentes nas matérias-primas utilizadas nos adubos fosfatados (Menzel, 1968; Ring, 1977; Mortvedt, 1986; Guimond \& Hardin, 1989; Guzman et al., 1995; Khan et al., 1998; San Miguel et al., 2003), do que decorre a transferência de urânio e tório para solos intensivamente fertilizados pela atividade agrícola (e.g. Rothbaum et al., 1979), rios e águas subterrâneas (e.g. Spalding \& Exner, 1976; Aguirre et al., 1995; Zielinski et al., 1997) e o conseqüente risco à saúde humana (e.g. Pfister et al., 1976; Amaral et al., 2005).

0 volume significativo de fertilizantes empregados na agricultura brasileira, considerada uma das maiores produtoras de grãos do mundo, sobretudo nos últimos dez anos, vem despertando 0 interesse da comunidade científica nacional no que concerne a quantificação de radioelementos em gesso agrícola e fertilizantes fosfatados, os quais encerram teores variados de nitrogênio, fósforo e potássio (Paschoa et al., 1984; Mazzilli et al., 2000; Yamazaki \& Geraldo, 2003; Saueia et al., 2004). 0 gesso agrícola (sulfato de cálcio di-hidratado), derivado do ácido fosfórico, contém em sua composição cálcio, enxofre e água em diferentes concentrações. 0 uso recente deste produto, cujos teores dependem da rocha utilizada para o seu fabrico e do tipo de cultura, tem por objetivo suprir os solos com cálcio e enxofre nos horizontes mais profundos, propiciando às plantas o desenvolvimento do sistema radicular, explorando maior volume de solos na busca por nutrientes e água (Nuernberg et al., 2002).

Neste contexto, trabalhos como os de Ferreira et al. (1997), Souza et al. (1997), Souza (1998) e Ferreira \& Souza (1999), procuraram investigar as relações de anomalias aerogamaespectrométricas de K, eU e eTh, detectadas por Ferreira (1991) na Quadrícula de Araras (SP), limitada pelas coordenadas geográficas $22^{\circ} 00^{\prime}$ e $22^{\circ} 30^{\prime}$ de latitude sul, $47^{\circ} 00^{\prime}$ e $47^{\circ} 30^{\prime}$ de longitude oeste, com o uso de fertilizantes fosfatados no plantio de cana-de-açúcar, o qual se desenvolve principalmente em solos de textura argilosa derivados do intemperismo de rochas básicas da Formação Serra Geral (soleiras de dolerito). Considerando que a distribuiç̧ão dos teores de radionuclídeos na paisagem pode ser susceptível a efeitos ambientais, geomorfológicos, geoquímicos, topográficos e variações litológicas (e.g. Dickson \& Scott, 1997; Wilford et al., 1997), o presente trabalho discute as relações espaciais, em ambiente de Sistemas de Informações Geográficas (SIG), de uma série de variáveis como drenagem, formações su- perficiais, gamaespectrometria (K, eU, eTh), geologia, imagens orbitais (LANDSAT TM), processos pedogenéticos, relevo, solos, susceptibilidade magnética, uso e ocupação do solo, assim como pretende contribuir com as pesquisas sobre contaminação radioativa de solos agrícolas derivada do uso intensivo e continuado de fertilizantes fosfatados em grandes culturas.

\section{CONTEXTO GEOLÓGICO}

A Bacia do Paraná é uma bacia intracratônica instalada no continente sul-americano (Figura 1), abrangendo uma área superior a $1.500 .000 \mathrm{~km}^{2}$. Seus limites atualmente abrangem tratos situados no centro-sul do Brasil, norte do Uruguai, mesopotâmia Argentina e Paraguai oriental. Sua história evolutiva está intimamente relacionada com as variações eustáticas do nível do mar, associada a eventos de subsidência ocorridos no domínio intraplaca, em resposta a esforços orogênicos paleozóicos na borda oeste do continente e a tafrogenia mesozóica responsável pela abertura do Oceano Atlântico Sul.

0 registro estratigráfico da Bacia do Paraná se distribui desde o neo-Ordoviciano ( $\pm 450 \mathrm{Ma}$ ) até o neo-Cretáceo $( \pm 65 \mathrm{Ma})$, representando um intervalo de cerca de $385 \mathrm{Ma}$, no qual estão registrados períodos descontínuos de sedimentação limitados por discordâncias regionais.

Milani (1997) considerou para 0 arcabouço aloestratigráfico da Bacia do Paraná um conjunto de seis superseqüências, as quais são delimitadas por superfícies de discordância de caráter inter-regional, são elas: Superseqüência Rio Ivaí (Caradociano Llandoveriano), Superseqüência Paraná (Lochkoviano - Frasniano), Superseqüência Gondwana I (Westphaliano - Scythiano), Superseqüência Gondwana II (Neoanisiano - Eonoriano), Superseqüência Gondwana III (Neojurássico - Berriasiano) e Superseqüência Bauru (Senoniano). As três primeiras superseqüências correspondem a grandes ciclos transgressivos/regressivos paleozóicos, enquanto as demais são representadas por unidades essencialmente continentais associadas a rochas vulcânicas (Figura 2).

0 embasamento da bacia é constituído pela interação de blocos crustais que foram soldados durante o processo colisional Brasiliano, por ocasião da consolidação do Gondwana. Os reflexos da acomodação isostática deste embasamento heterogêneo, devido ao acúmulo de sedimentos, foram marcantes durante a evolução da bacia.

Segundo Milani (1997) e Milani \& Ramos (1998), a Bacia do Paraná, apesar de ser suportada por um embasamento cratônico desde sua implantação, foi influenciada em sua vizinhança por 


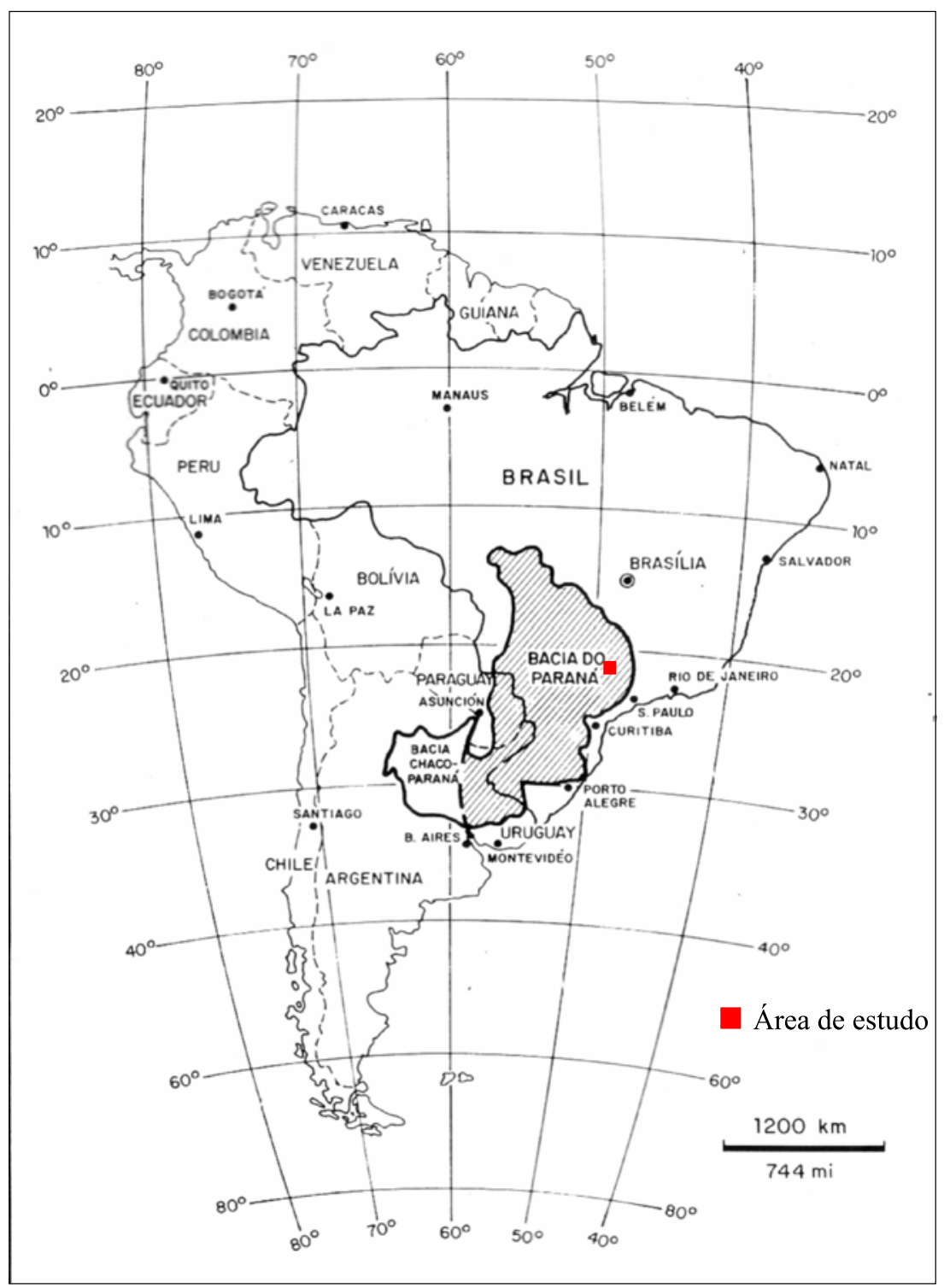

Figura 1 - Mapa da Bacia do Paraná na América do Sul indicando a localização da área de estudo (adaptado de Milani, 1997).

cinturões colisionais ativos e bacias de antepaís a eles relacionadas. Ciclos orogênicos distintos ensejaram a reativação transtensiva de zonas de fraqueza antigas, além de mudanças nas taxas de subsidência da bacia.

A geologia da Quadrícula de Araras (SP) está inserida na Superseqüência Gondwana I, a qual inclui formações do Carbonífero, do Permiano e do eo-Triássico; na Superseqüência Gondwana III (Formação Serra Geral, soleiras de diabásio), além de formações do Terciário e depósitos aluvionares. Uma descrição sucinta destas formações é apresentada na seção Geologia do item Síntese da Área de Estudo.

\section{SÍNTESE DA ÁREA DE ESTUDO}

\section{Geologia}

A Quadrícula de Araras situa-se no contexto da Bacia do Paraná. É constituída de formações desde o Paleozóico até o Cenozóico.

0 Paleozóico na área de estudo compreende as formações Itararé/Aquidauana e Tatuí do Grupo Tubarão e as formações Irati e Corumbataí do Grupo Passa Dois. 0 Mesozóico é representado pela Formação Pirambóia e diques e soleiras de diabásio da Formação Serra Geral (Grupo São Bento). Nas coberturas cenozóicas encontram-se a Formação Rio Claro e correlatas, bem como os sedimentos aluvionares. 


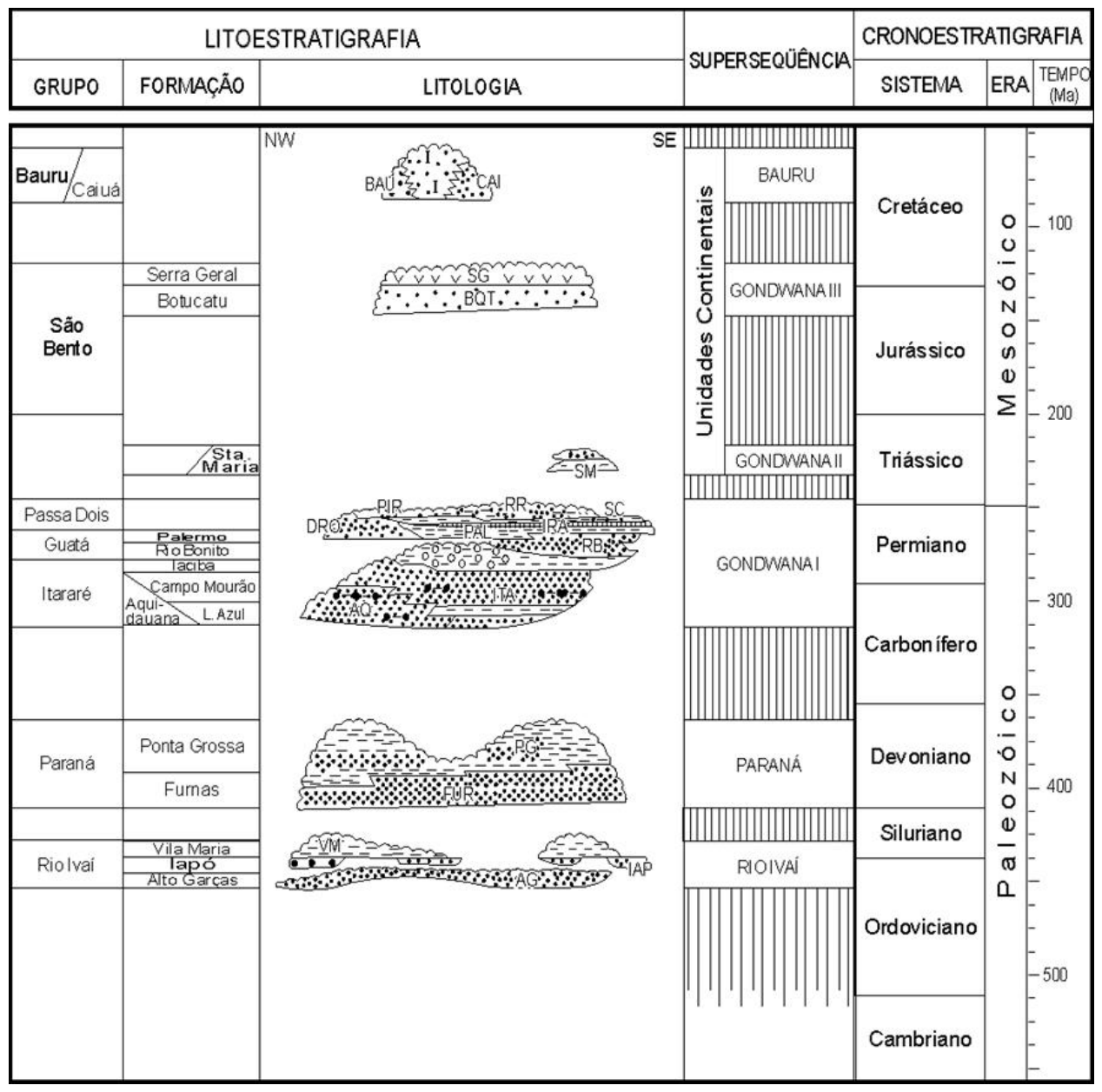

Figura 2 - Coluna Estratigráfica da Bacia do Paraná (adaptada de Milani, 1997).

A Figura 3 mostra o mapa geológico da região de estudo. Os dados foram oriundos do Mapa Geológico da Folha Campinas (IPT, 1993), escala 1:250.000. Assim, estão representadas as seguintes unidades litoestratigráficas:

Qa: Aluviões recentes em geral, incluindo depósitos de terraços; TQp: Formação Piraçununga - depósitos continentais incluindo acumulações elúvio-coluvionares de natureza areno-argilosa;

TQr: Formação Rio Claro - arenitos, arenitos conglomeráticos, arenitos argilosos e pequenas intercalações argilosas;

JK $\beta$ : Intrusivas Básicas Tabulares - soleiras diabásicas;

$T_{\text {RJp }}$ : Formação Pirambóia - depósitos fluviais e de planícies de inundação incluindo arenitos finos a médios, avermelhados, síltico-argilosos, de estratificação cruzada ou plano-paralela, níveis de folhelhos e arenitos argilosos de cores variadas e raras intercalações de natureza areno-conglomerática. Esta unidade, segundo Landim et al. (1980 apud Brollo, 1991), marca o início da deposição mesozóica pré-vulcânica no estado de São Paulo.

Pc: Formação Corumbataí - depósitos possivelmente marinhos de planícies de maré, incluindo argilitos, folhelhos e siltitos finos, arroxeados ou avermelhados, com intercalações de bancos carbonáticos, silexíticos.

Pi: Formação Irati - siltitos, argilitos e folhelhos sílticos de cor cinza clara a escura, folhelhos pirobetuminosos, localmente em alternância rítmica com calcários cremes, silicificados, e restritos níveis conglomeráticos, membro pelítico persistente na base. IPT (1981 apud Brollo, 1991) apresenta duas hipóteses para o ambiente de sedimentação da Formação Irati. A primeira diz que 0 ambiente é marinho de águas rasas, em bacia confinada, com clima favorável à precipitação de calcários, e condições físico-químicas favoráveis à dolomitização e acúmulo de matéria orgânica geradora dos pirobetumes. Pela outra hipótese, 0 ambiente de sedimentação seria de lagoas marginais em lenta subsidência, 
com estreita ligação com o mar, numa região de relevo baixo, coberta de vegetação luxuriante e sujeita a ritmos climáticos.

Ptt: Formação Tatuí - depósitos marinhos com estratificação plano-paralela, predominando siltitos, arenitos finos em parte concrecionados, calcários, sílex; cor vermelha arroxeada na parte inferior e esverdeada na parte superior;

CPi: Grupo Itararé - indiviso: depósitos glaciais, continentais, glácio-marinhos, fluviais, deltáicos, lacustres e marinhos, compreendendo principalmente arenitos de granulação variada, imaturos, passando a arcóseos; conglomerados, diamictitos, filitos, siltitos, folhelhos e ritmitos.

CPa: Formação Aquidauana - depósitos continentais predominantemente arenitos vermelhos arroxeados, médios a grossos, feldspáticos e subordinadamente arenitos finos, conglomerados, siltitos, folhelhos rítmicos e diamictitos.

\section{Solos}

Os dados pedológicos (Oliveira et al., 1981) mostram que os Latossolos ocupam maior área na Quadrícula de Araras (SP). Dentre as classes, 0 Latossolo Roxo compreende aquele originado pela pedogênese sobre soleiras de diabásio, possui teores elevados de $\mathrm{Fe}_{2} \mathrm{O}_{3}$ (> 18\% e < 40\%), $\mathrm{MnO}$ e, usualmente, de $\mathrm{TiO}_{2}$, com forte atração magnética e predominantemente de textura argilosa a muito argilosa. A grande quantidade de óxidos de ferro, ou de ferro e alumínio e a textura argilosa, favorecem a adsorção de fósforo e radionuclídeos. Os Latossolos Vermelhos-Escuros de textura argilosa são provenientes do intemperismo e retrabalhamento de sedimentos finos: argilitos e siltitos com contribuição variada de rochas básicas, encontrando-se, por isso, solos com diversos teores de ferro total. Os de textura média se originam de materiais mais grosseiros, resultantes de arenitos e siltitos, também com contribuição variada de rochas básicas. Os Latossolos Vermelhos-Amarelo ocorrem nas porções mais baixas e planas. A Terra Roxa Estruturada constitui os solos argilosos ou muito argilosos, derivados de rochas básicas, com teores relativamente altos de $\mathrm{Fe}_{2} \mathrm{O}_{3}$ (15\%, mínimo constatado) e de $\mathrm{TiO}_{2}$ $(1,5 \%)$, com baixo gradiente textural. A Figura 4 mostra as principais classes de solos da área de estudo.

\section{Uso dos solos}

A Figura 5 mostra o mapa de uso dos solos da Quadrícula de Araras. Observa-se que há o predomínio do cultivo de cana-deaçúcar. Culturas perenes, como aquela advinda da citricultura, apresentam menor fragmentação quando comparadas às culturas temporárias. Já o reflorestamento, predominando a leste da área, sobressai-se com relação a atividades de pastagem que se mostram bem fragmentadas por toda a Quadrícula. A cultura de cana-de-açúcar se desenvolve principalmente sobre os solos mais evoluídos (Latossolos), de textura argilosa, provenientes de materiais oriundos de rochas básicas. Pastagem e reflorestamento ocupam áreas mais movimentadas e menos adequadas à lavoura.

\section{MATERIAIS E MÉTODOS}

\section{Materiais}

Para o desenvolvimento da pesquisa foram utilizadas as seguintes bases de dados:

- dados aerogamaespectrométricos digitais em cps (contagens por segundo) de K, eU, eTh e Contagem Total (CT), obtidos do levantamento aerogeofísico Projeto São Paulo - Rio de Janeiro, executado pela ENCAL S.A. Consultoria e Aerolevantamentos, entre os anos de 1978 e 1979, para a Companhia de Pesquisa de Recursos Minerais - CPRM (Anjos \& Mourão, 1988);

- imagem do satélite LANDSAT 5 sensor TM, bandas 3 (vermelho do visível), 4 (infra-vermelho próximo) e 5 (infra-vermelho médio); resolução espacial de $30 \mathrm{~m}$; órbita/ponto 220/75, data aquisição 29/08/1992;

- mapa geológico da Folha Campinas (SF 23-Y-A), escala 1: 250.000 (IPT, 1993);

- mapa do levantamento semi-detalhado de solos da Quadrícula de Araras (SP) (SF 23-Y-All), em escala 1:100.000 (Oliveira et al., 1981);

- formações superficiais:

a) Leme: Formações Geológicas Superficiais - Folha Geológica de Leme (SF 23-Y-A-II-1), escala 1:50.000 (IG, 1980);

b) Rio Capetinga: Formações Geológicas de Superfície, FoIha Geológica de Rio Capetinga (SF 23-Y-A-II-2), escala 1:50 000 (IG, 1981);

c) Araras: Formações Geológicas de Superfície - Folha Geológica de Araras (SF 23-M-II-3), escala 1:50.000 (IG, 1987).

- mapa de uso do solo, em escala 1: 250.000, gentilmente cedido pelo IPT (1993) e obtido a partir da interpretação da banda 5 (IVM) da imagem do satélite LANDSAT 5 (órbita/ponto 220/75 de 28/08/1992); 


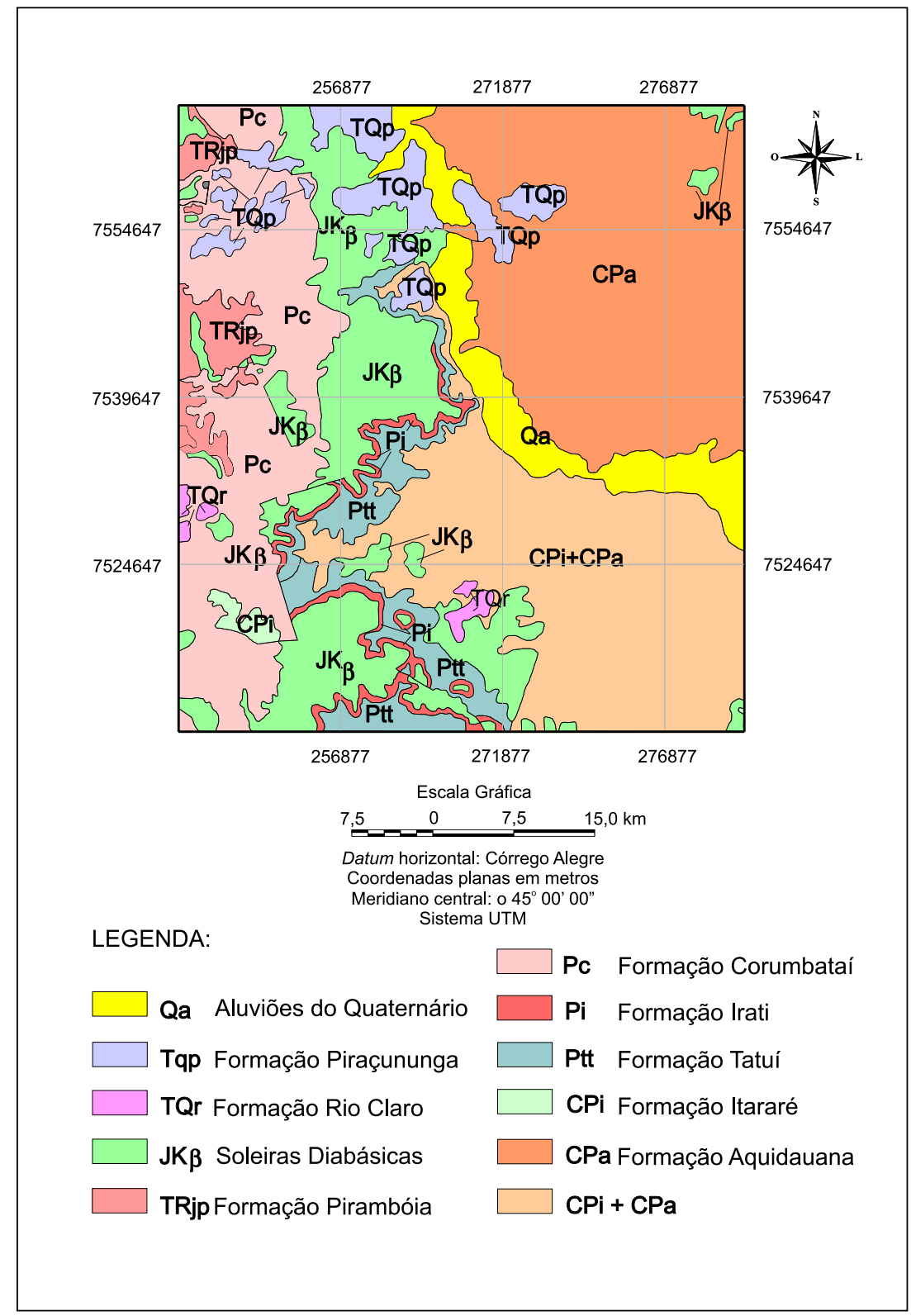

Figura 3 - Mapa geológico da região de Araras (adaptado de IPT, 1993).

- folhas topográficas:

a) Leme: Folha SF 23-Y-A-II-1, escala 1:50.000 (IBGE, 1971a);

b) Araras: Folha SF 23-M-II-3, escala 1:50.000 (IBGE, 1969);

c) Rio Capetinga: Folha SF 23-Y-A-II-2, escala 1:50.000 (IBGE, 1971b);

d) Conchal: Folha SF 23-Y-A-II-4, escala 1:50.000 (IBGE, 1974).

\section{Métodos}

\section{Aerogamaespectrometria}

0 levantamento aerogamaespectrométrico, associado ao aeromagnético, foi realizado pela empresa ENCAL (1979) para a CPRM (Anjos \& Mourão, 1988), a qual utilizou três aeronaves. A área foi dividida em cinco segmentos.

Este levantamento foi executado com espaçamento aproximado de $1 \mathrm{~km}$ entre as linhas de vôo, posicionadas segundo N-S, e a uma altura média de $150 \mathrm{~m}$ sobre o terreno. Foram levantados 


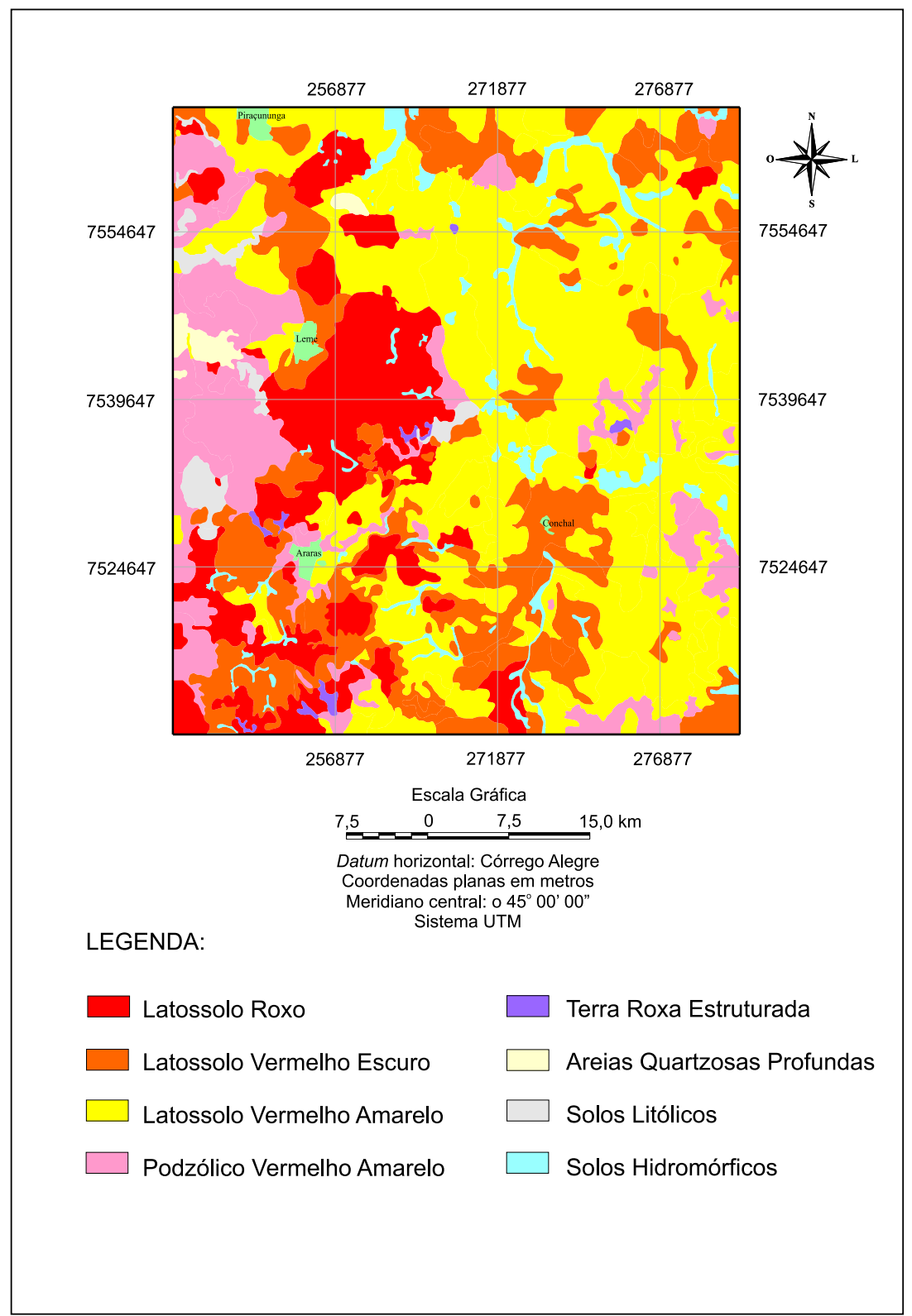

Figura 4 - Mapa de solos da área de pesquisa (adaptado de Oliveira et al., 1981).

cerca de $94.031 \mathrm{~km}$ de perfis, que correspondem a aproximadamente 982.000 registros.

Na área de interesse deste trabalho foi utilizado um detector de iodeto de sódio ativado a tálio [Nal(TI)], com 3072 polegadas cúbicas para a detecção das radiações gama nos canais do potássio $\left(K^{40}-1,46 \mathrm{MeV}\right)$ e equivalentes de eU $(\mathrm{Bi}-1,76 \mathrm{MeV})$ e eTh ( $\mathrm{Tl}-2,61 \mathrm{MeV})$, respectivamente. 0 levantamento dessa sub-área foi efetuado entre junho de 1978 e fevereiro de 1979, tendo sido utilizado um avião do tipo Bandeirantes (sub-áreas $4 \mathrm{e}$
6) e dois outros do tipo Islander (sub-área 3). Foram levantados em torno de $52.400 \mathrm{~km}$ de perfis, perfazendo cerca de 540.200 registros.

0 processamento dos dados executados por Anjos \& Mourão (1988) envolveu uma série de etapas, cada qual com a aplicação de um conjunto de programas. Além da formatação das fitas originais, da análise crítica dos dados, da correção dos dados da composição do registro mestre e da transformação das coordenadas planas em geográficas, foram utilizadas as seguin- 


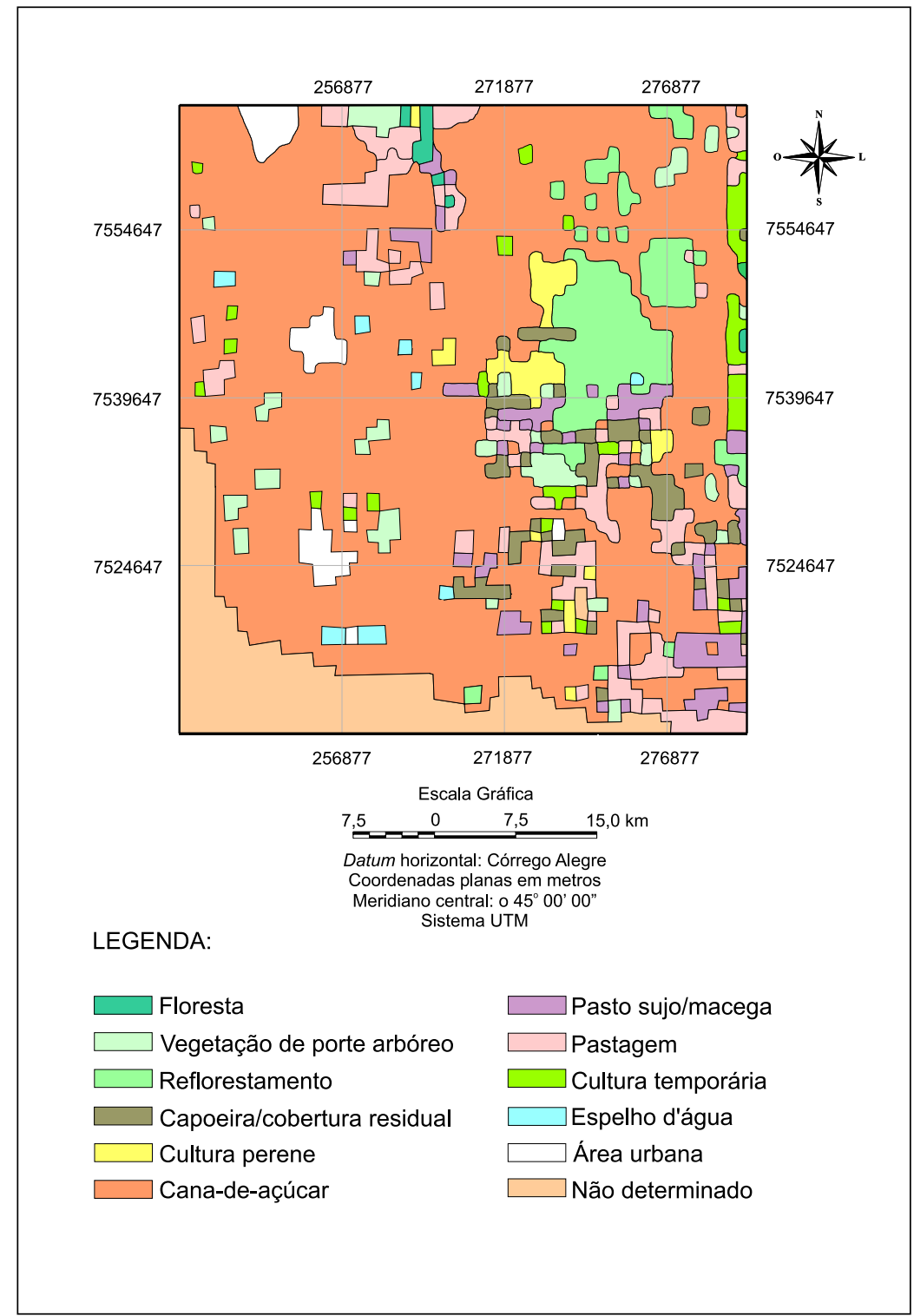

Figura 5 - Mapa de uso dos solos da região de Araras (adaptado de IPT, 1993).

tes correções gamaespectrométricas: redução do ruído de fundo atmosférico, correção do efeito Compton e correção altimétrica (150 m).

Assim, 0 uso dos dados aerogamaespectrométricos (unidades em cps) pertinente a Quadrícula de Araras sob a forma de imagens, exigiu uma etapa de pré-processamento dos dados brutos, na geração de malhas de $125 \times 125$ metros, pelo método de interpolação da curvatura mínima (Briggs, 1974), em software específico para dados aerogeofísicos, como o Geosoft, versão 4.03.

Cabe ressaltar que esta etapa de pré-processamento não incluiu as correções de rotina de levantamentos aerogamaespec- trométicos, como as de altura, de background, e do efeito Compton, uma vez que os dados digitais brutos de $\mathrm{K}$, eU, eTh e contagem total, foram cedidos pela CPRM já corrigidos.

Almejando-se estabelecer o intervalo anômalo de K, eU e eTh, procedeu-se o fatiamento (reclassificação ou reclass) das imagens aerogamaespectrométricas originais, cedidas por Ferreira (1991). Assim, foram estabelecidas 5 (cinco) classes baseadas na média $(x)$ e no desvio padrão $(s)$, cujos valores foram os seguintes: menores que $x$, entre $x \mathrm{e} x+1 s$, entre $x+1 s$ e $x+2 s$, entre $x+2 s$ e $x+3 s$ e superiores a $x+3 s$, como será visto nos resultados e discussões. Sobre as imagens geofísicas, também 
aplicou-se técnicas de processamento digital de imagens (PDI), como composições coloridas e classificação não supervisionada (CLUSTER), objetivando detectar valores anômalos simultâneos das variáveis, para extrair tematicamente as classes representativas de ocorrência das anomalias.

A alocação dos canais do $\mathrm{K}$, do eU e do eTh, no canal do $\mathrm{R}$ (vermelho), $\mathrm{G}$ (verde) e B (azul), almejou mostrar apenas as coincidências de altos valores anômalos. Assim, pela teoria básica das cores, a combinação do vermelho com o verde resulta na cor amarela; a combinação do vermelho com o azul, na cor magenta; azul com verde, na cor ciano.

Cabe ressaltar que antes de realizar a composição colorida, os dados aerogamaespectrométricos, em cps, de $\mathrm{K}$, eU e eTh foram transformados em imagens monocromáticas de 8 bits cada, onde 0 espectro de valores dos dados foi convertido para o intervalo de 256 níveis de cinza. Esta transformação representou uma compressão da resolução original das variáveis geofísicas, a qual deve ser levada em consideração.

0 CLUSTER no software Idrisi for Windows, trabalha com imagens compostas a partir de três canais, produzidos pelo módulo COMPOSIT e usa uma técnica de seleção através do pico do histograma.

$\mathrm{Na}$ composição colorida da imagem gama (K-eU-eTh), efetuou-se a operação CLUSTER (classificação com base nos canais) escolhendo-se a opção de deixar os grupos menos significativos e realizar uma classificação mais restrita (opção fine), para gerar um número maior de grupos, de acordo com Souza (1998).

Após a identificação das classes de interesse, a imagem obtida foi reclassificada pelo módulo RECLASS, o qual reclassifica os dados armazenados nas imagens pela pré-definição dos valores. Selecionou-se as classes correspondentes valores elevados e coincidentes de $\mathrm{K}$ e eTh, bem como valores elevados e coincidentes de $\mathrm{K}$, eU e eTh da imagem classificada. Este módulo RECLASS também foi usado para se identificar áreas anômalas de cada variável geofísica separadamente, como apresentado anteriormente.

\section{Relevo}

Mediante os dados analógicos representados pelas cartas topográficas citadas no item materiais, realizou-se a digitalização das curvas de nível com auxílio de mesa digitalizadora e software do tipo CAD. Posteriormente, as isolinhas, espaçadas em 20 metros, já em meio digital e cotadas, sofreram o processo de modelagem numérica em ambiente SIG mediante a interpolação das amostras. 0 interpolador usado, média ponderada, resultou em um arquivo matricial, onde os níveis de cinza mais escuros representavam as cotas mais baixas do terreno e os tons mais claros as porções mais elevadas, quando a paleta de cores era do tipo grey scale. Este produto serviu para uma avaliação qualitativa do padrão de drenagem das áreas-alvo, quando técnicas de sombreamento foram aplicadas, bem como foi utilizado para integrar os dados aerogamaespectrométricos, quando este era usado como plano de textura às informações altimétricas interpoladas.

\section{Solos e Geologia}

Para os mapas de solos e geologia citados no item materiais, realizou-se a digitalização (uso de mesa digitalizadora) em ambiente SIG. Cada unidade de mapeamento de solo (24 unidades de mapeamento), ou cada litologia (11 unidades litoestratigráficas) ficaram representadas por polígono(s), ou arco(s) fechado(s), que sofreram processo de edição topológica, os quais pontos interiores foram identificados de acordo com a informação que cada mapa dispunha. Esta etapa serviu para associar os atributos da legenda para cada região de cada polígono digitalizado, para que operações nos dados e entre as variáveis espaciais, como tabulação cruzada (solos versus geologia); lógicas booleanas com operador 〈AND〉 (classes solos versus determinadas classes de anomalias geofísicas); máscaras (determinadas classes de solos e litologias sobre imagens de satélite), etc. pudessem ser realizadas e auxiliar a análise.

\section{Formações Superficiais}

Os mapas de formações superficiais, antes da sua digitalização, foram previamente interpretados em face da sua riqueza de informações e conseqüentemente complexidade envolvida. Foi necessário extrair em grupos aquelas informações que considerassem somente unidade litoestratigráfica, granulometria e característica do material inconsolidado (colúvio, alúvio, regolito). São mapas que, de acordo com Oliveira (1981 apud Freitas et al., 1979), informam toda formação ou depósito continental, marinho ou de ambas origens, móveis ou secundariamente consolidadas, que tenham ou não sofrido a ação de agentes de transporte e originado da desagregação física e/ou da alteração química das rochas.

Estes tipos de mapas mostram, além da unidade litoestratigráfica no recorte espacial, a sua autoctonia, espessura, bem como a granulometria do material coletado no horizonte B.

Ressalta-se que antes da digitalização, combinou-se todas as informações geológicas com a autoctonia e a granulometria, não discriminando a espessura. A Figura 6 mostra 0 esquema de 
cruzamento do mapa de formações superficiais. Para a folha de Leme, obteve-se 27 classes; para a folha de Araras, 22 classes; para a folha de Rio Capetinga, 17 classes.

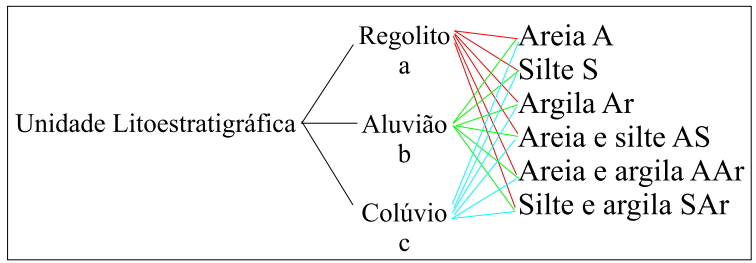

Figura 6 - Esquema de cruzamento dos dados de formações superficiais.

A Figura 7 mostra o produto final, correspondente às folhas Leme, Araras e Rio Capetinga, citadas no item materiais, após eleição das classes, compondo aproximadamente $3 / 4$ da área de estudo.

Os polígonos gerados foram sobrepostos às imagens geofísicas de $\mathrm{K}$, eU e eTh, para averiguar qual a granulometria e a característica do material intemperizado que ocorriam sobre as áreas anômalas.

\section{Uso do solo}

Dispondo das imagens de satélite (LANDSAT 5) em meio digital, bem como mapa de uso e cobertura gentilmente fornecido em pelo IPT (1993) em meio analógico, compilou-se o mapa de uso da área de estudo. Sobre a imagem de satélite, técnicas de PDI foram aplicadas com o objetivo de facilitar a interpretação e distinção dos diferentes materiais da superfície terrestre, procurando sempre levar em consideração os elementos de interpretação de imagens (textura, forma, tamanho, padrão, etc.). As técnicas de PDI foram: georeferenciamento (interpolador da fase reamostragem vizinho mais próximo); composições coloridas falsa-cor, aumento linear de contraste, entre outras. Entretanto o mapa do IPT (1993) já disponível, e por apresentar maior detalhamento de informação, foi digitalizado e usado como base de dados para a composição do plano de informação Uso do Solo.

\section{Geofísica Terrestre}

Os trabalhos de campo envolveram o reconhecimento da área, gamaespectrometria terrestre, visitas a usinas de cana-de-açúcar, amostragem de solos em pontos inseridos ou não em áreas anômalas, bem como a medição da susceptibilidade magnética de alguns solos e rochas através de um indicador de susceptibilidade (k).

A gamaespectrometria terrestre, para a detecção em contagens por segundo do potássio, do equivalente de urânio, do equivalente do tório e da contagem total (CT) com tempo de integração de 10 segundos, foi realizada em perfis com pontos espaçados de aproximadamente $1 \mathrm{~km}$ (Figura 8). Os instrumentos utilizados foram o GRS-500 Differencial Gamma-Ray Spectrometer/Scintillometer (Scintrex, Canadá) e o susceptibilímetro Kappameter KT-45 (Geofyzika, República Checa), ambos pertencentes ao LPGA/UFPR. Para cada ponto realizou-se três leituras referentes a TC 2 (contagem total), $\mathrm{K}$, eU, eTh e $\mathbf{k}$. As medidas gamaespectrométricas foram tomadas com tempo de integração de 10 segundos. 0 uso do susceptibilímetro objetivou diferenciar as classes de solos como Latossolo Roxo, Terra Roxa Estruturada e Latossolo Vermelho Escuro.

0 GRS-500 possui um cristal de Nal(TI) com volume de $124 \mathrm{~cm}^{3}$. As janelas de energia são: TC1 (contagem total acima de 0,08 MeV); TC2 (contagem total acima de 0,40 MeV); K (entre 1,35 e 1,59 MeV); U (entre 1,65 e 1,87 MeV); Th (entre 2,45 e 2,79 MeV).

\section{Análises Radioquímicas}

Para as determinações do urânio natural e do tório natural em amostras de solos e fertilizantes, utilizou-se o método fluorimétrico para 0 urânio e 0 espectrofotométrico para 0 tório. As referidas análises foram realizadas no Laboratório do Serviço de Proteção Radiológica (SPR), Instituto de Engenharia Nuclear (IEN), Comissão Nacional de Energia Nuclear (CNEN).

\section{RESULTADOS E DISCUSSÕES}

\section{Processamento Digital de Imagens e Integração em Ambiente SIG}

As informações de uso do solo, bem como as visitas a campo e a usinas revelaram que a principal atividade agrícola realizada sobre os Latossolos Roxos é o cultivo, por várias décadas, de cana-de-açúcar. Tal cultura é tratada com doses elevadas de fertilizantes, principalmente dos tipos fosfatados. As doses de fertilizantes aplicadas dependem do sistema de cultivo envolvido. Assim, quantidades maiores de fosfatos são aplicadas no sistema cana-planta, que é um sistema implantado geralmente em 20\% da área que está sendo cultivada. Neste tipo de cultivo são aplicados $700 \mathrm{~kg} / \mathrm{alq}$ de formulações (N-P-K) 4-20-20 ou 5-25-25. Em algumas áreas, adicionalmente, aplicam-se $200 \mathrm{~kg} / \mathrm{alq}$ de superfosfatos. Quando o sistema de produção é do tipo cana-soca ("rebrote"), utilizam-se formulações com baixas concentrações de P e elevadas de N e K, como 14-07-28, 18-00-36, 20-05-20.

A presença de radionuclídeos em fertilizantes fosfatados, a variação dos teores de radionuclídeos conforme o processo de produção e a origem da matéria-prima, a utilização de fontes fos- 


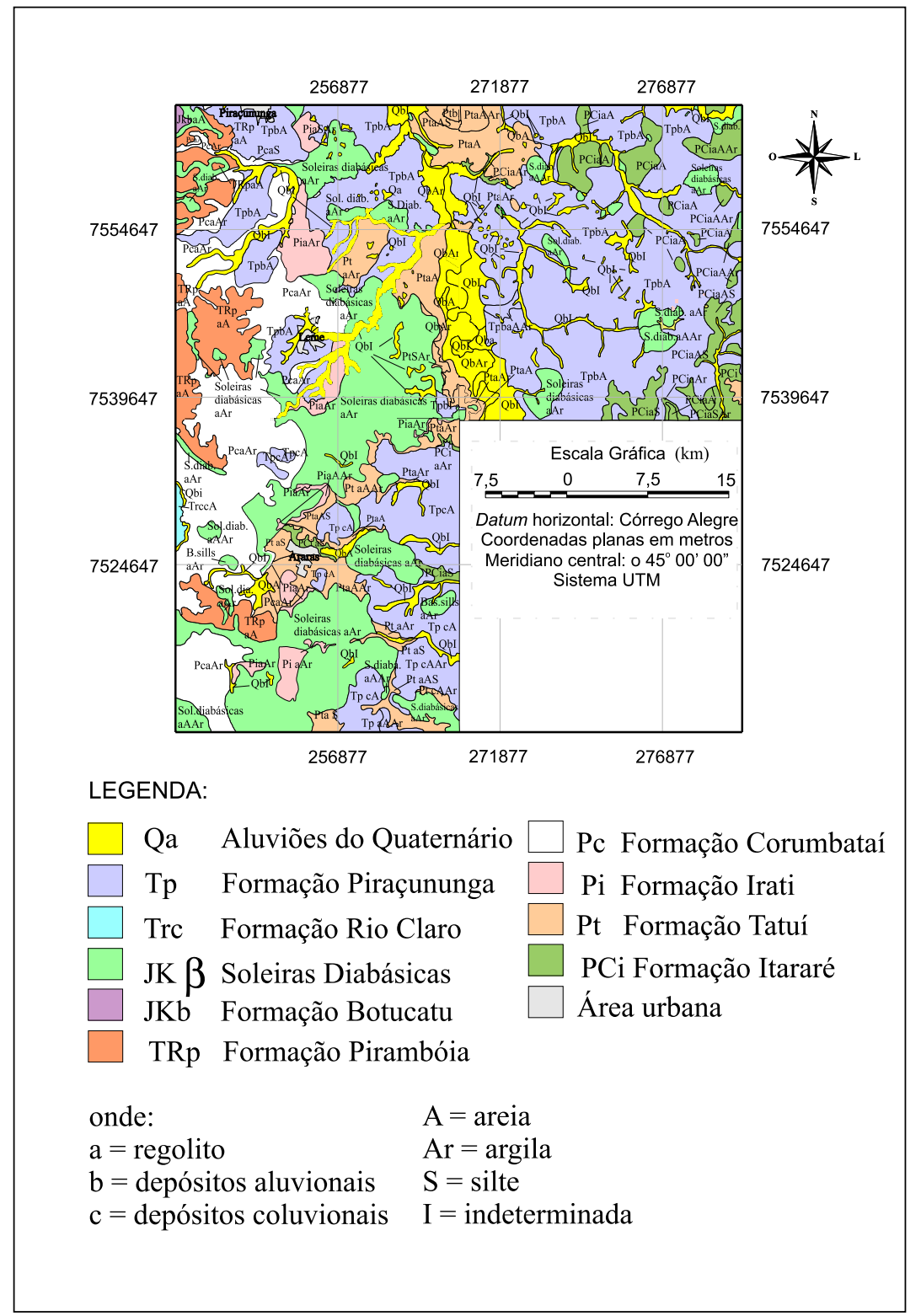

Figura 7 - Mapa de Formações Superficiais (adaptado de IG, 1980, 1981, 1987).

fatadas nacionais e importadas, o comportamento geoquímico dos radionuclídeos frente aos processos pedogenéticos, aliados a um histórico de uso intensivo de fertilizantes nestas áreas de cana-de-açúcar, levou a necessidade de selecionar áreas ou regiões consideradas geofisicamente anômalas e integrá-las aos dados digitais de geologia (para mostrar que 0 material de origem era uma rocha básica, sobre a qual a literatura revelava teores baixos de radionuclídeos), de solos (Latossolos Roxos são solos profundos, bem intemperizados, provenientes da alteração de rochas básicas e com elevados teores de $\mathrm{Fe}_{2} \mathrm{O}_{3}$ ), relevo (para referenciar a situação de relevo em que se encontravam as anomalias e os solos), formações superficiais (para revelar se estas anomalias ocorriam sobre colúvios, alúvios ou material in situ, bem como a influência da granulometria argilosa).

Assim, a composição colorida RGB de K, eU e eTh, como verificado na Figura 9, mostra que a coloração magenta representa os teores elevados e coincidentes de $\mathrm{K}$ e eTh. A classificação não supervisionada desta composição colorida (Figura 10a), permitiu a seleção do cluster correspondente a estes valores elevados e coincidentes de radionuclídeos, sobre o qual foi adicionado 


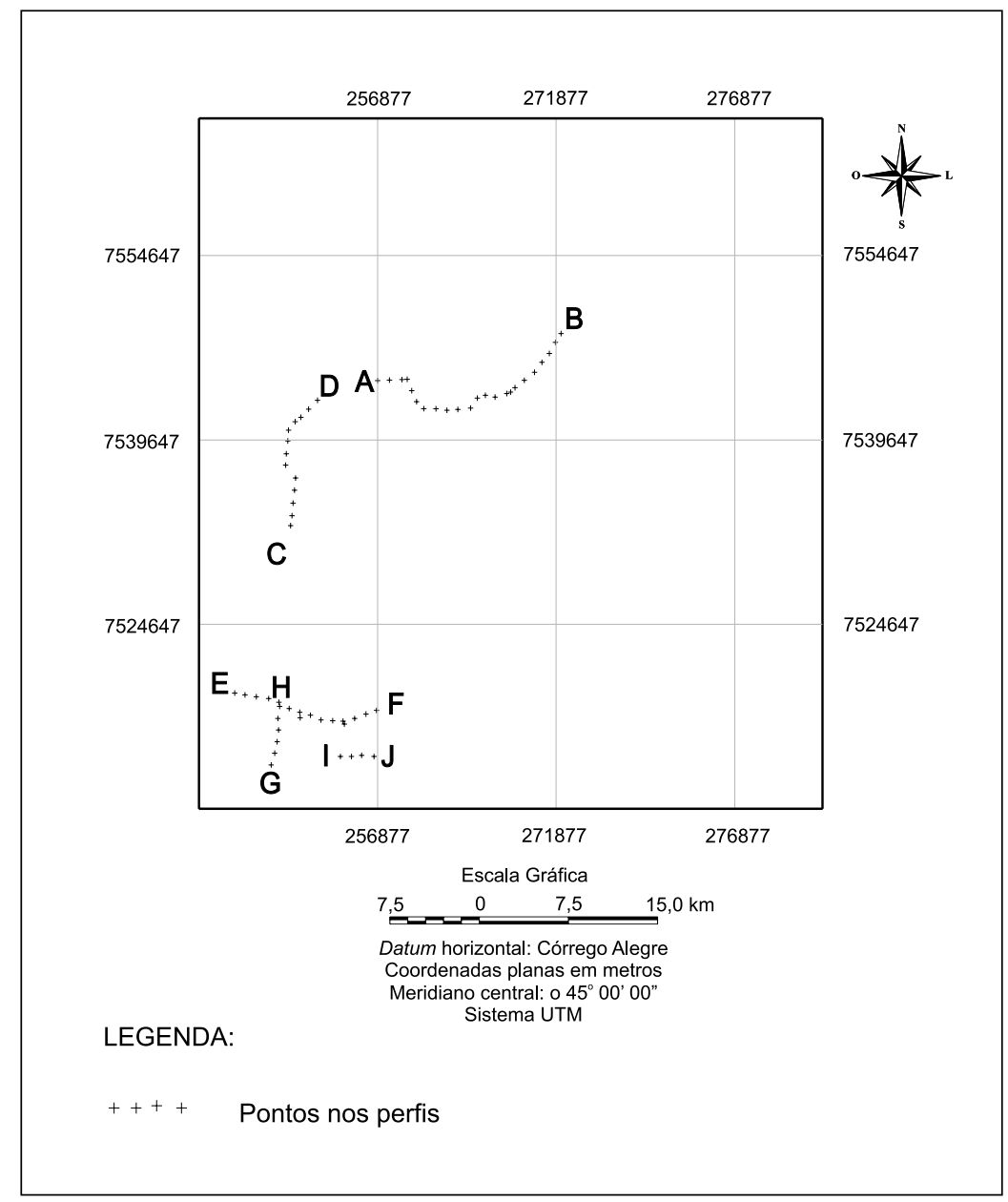

Figura 8 - Perfis terrestres.

o layer Aluviões do Quaternário (Figura 10b), oriundo do mapa geológico, sobre o qual encontra-se uma associação de três classes de solos: Latossolos Vermelhos-Amarelos (Unidade Campininha LV-6), Solos Hidromórficos (Hi) e Cambissolos (Cb-2).

A unidade LV-6 refere-se a um Latossolo Vermelho-Amarelo câmbico que ocorre em relevo aplainado de terraço. Estes se desenvolvem em material aluvionar de antigos terraços situados ao longo das margens do rio Moji-Guaçu, em cotas suficientemente elevadas para ficarem atualmente a salvo de adições fluviais. As principais culturas são cana-de-açúcar e cítrus. Estes solos apresentam teores médios de argila e uma capacidade de troca catiônica mais elevada que os outros Latossolos de textura semelhante, devido a maior contribuição da fração orgânica. Segundo Peres et al. (1980 apud Oliveira et al. 1981), uma amostra composta de Latossolo câmbico coletado nessa quadrícula apresentou $93 \%$ de quartzo, $0,7 \%$ de mica e $1,7 \%$ de feldspato. Oli- veira et al. (1981), em quatro amostras analisadas, obtiveram uma variação de 1 a $3 \%$ de feldspatos e as micas não ultrapassaram 4\%. A unidade Sete Lagoas (Cb-2), refere-se a um Cambissolo Álico com presença marcante de mica, especialmente a partir do horizonte B1 $(A B)$. Esses solos situam-se ao longo das margens do rio Moji-Guaçu, relacionados ao nível I dos antigos terraços, segundo Peres et al. (1980 apud Oliveira et al. 1981). Os solos hidromórficos desta quadrícula, por se desenvolverem em planícies aluvionares onde a ocorrência de estratos é comum, apresentaram diversidade textural bastante acentuada.

No caso da presente pesquisa, os terraços são antigos e apesar do material não ser oriundo de fontes graníticas ou metamórficas como a área estudada por Wilford et al. (1997), elevados valores de $\mathrm{K}$ foram observados. É possível uma concentração de material micáceo oriundo do embasamento. Segundo os autores mencionados, o potássio é quimicamente móvel e solúvel 


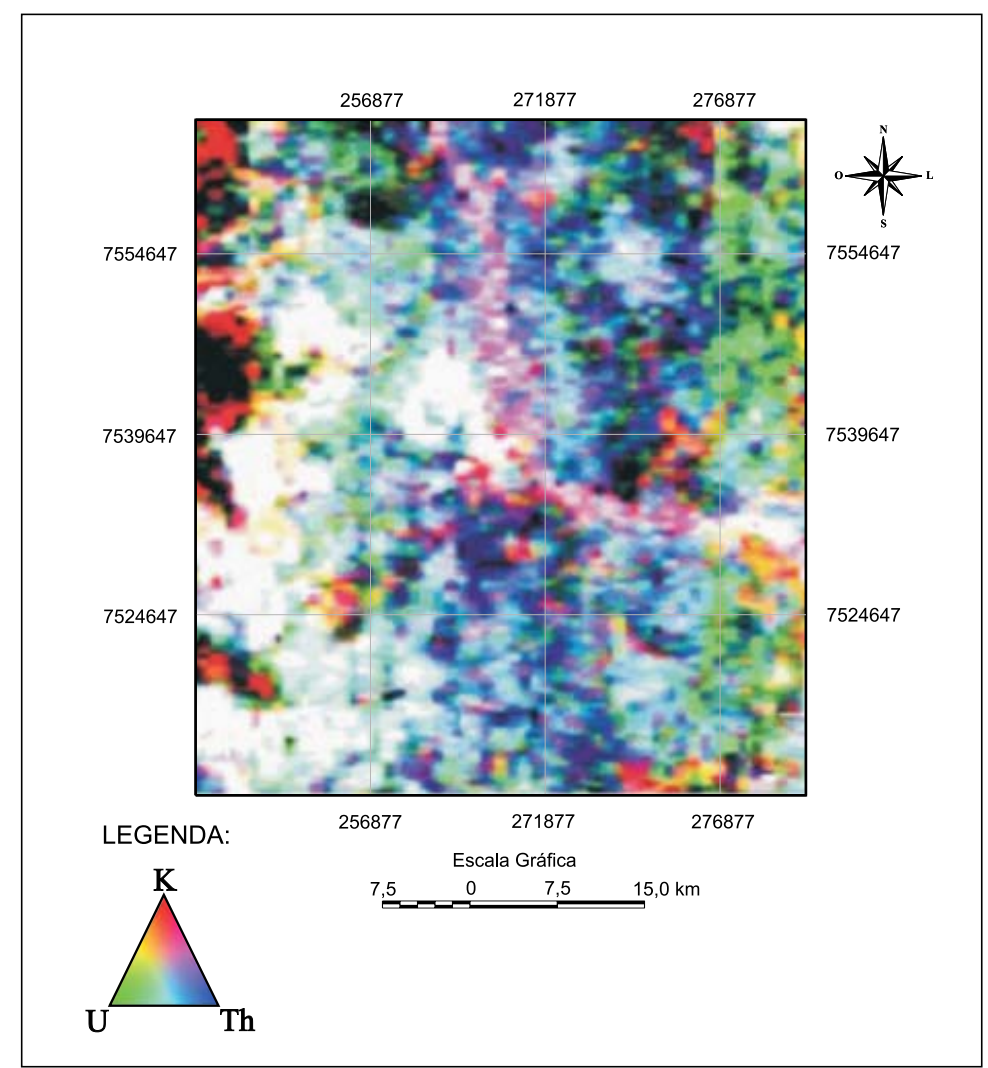

Figura 9 - Composição Colorida R(K-cps), G(eU-cps) e B(eTh-cps) da região de Araras.

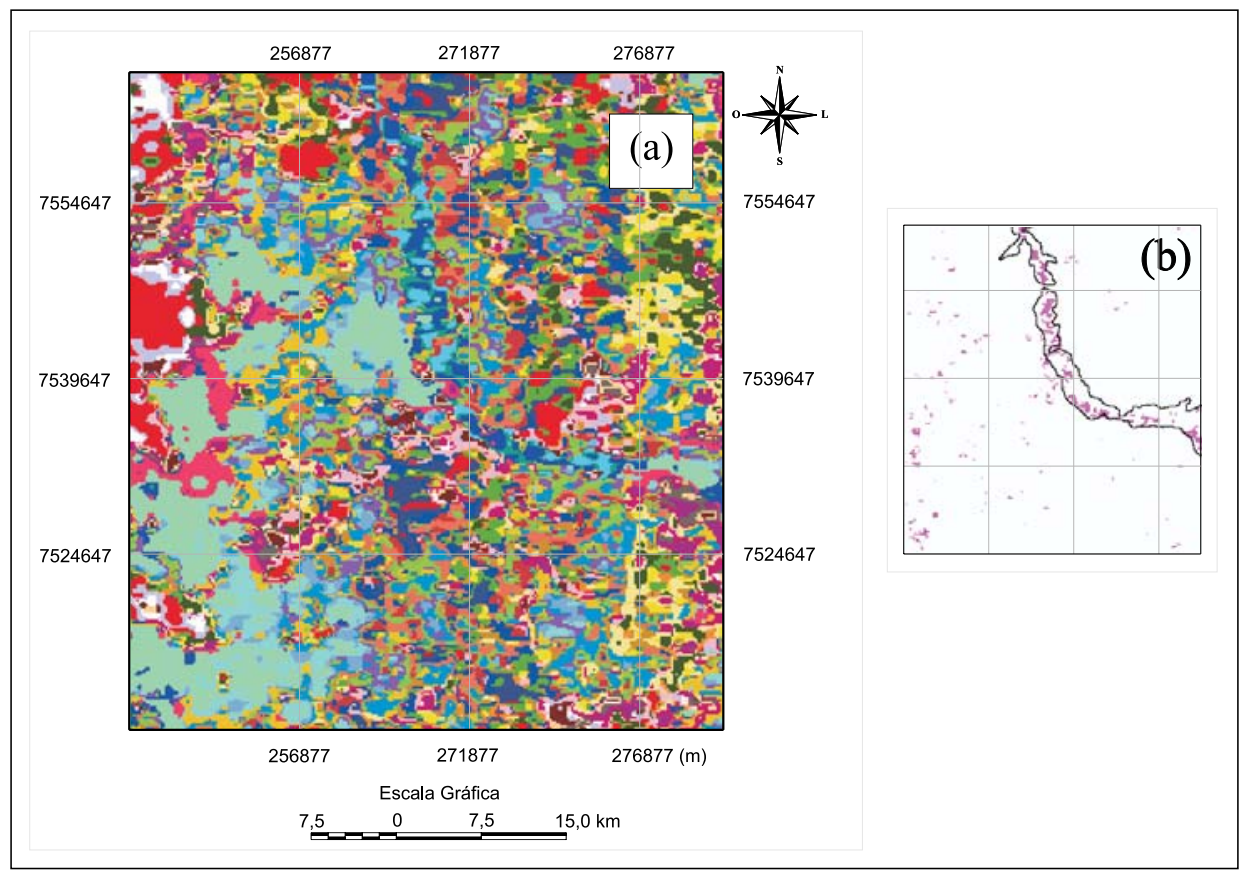

Figura 10 - Classificação com base nos canais K(cps), eU(cps) e eTh(cps), ressaltando o layer Qa (b - Quaternário). 
na maioria das condições de intemperismo. Durante tais processos o K é desprendido de minerais primários, como os feldspatos potássicos e micas e adsorvido em minerais de argila, como a ilita, montmorilonita e, em menores proporções, na caulinita. Sugere-se, portanto, que a ocorrência desta anomalia de $\mathrm{K}$ nestes terraços seja oriunda do transporte deste radionuclídeo (elevada atividade deposicional), proveniente da fertilização potássica das porções mais elevadas do terreno, bem como da contribuição do potássio presente nos felsdspatos e micas dos solos drenados pelo rio Moji-Guaçu.

A ocorrência de anomalias de tório ao longo do curso do rio Moji-Guaçu, obtida pela classificação não supervisionada da composição colorida RGB-KeUeTh, pode ser explicada pela relação deste radionuclídeo com materiais orgânicos. Como mencionado, a elevada capacidade de troca de cátions dos LV6 (ambiente oxidante) e a ocorrência de solos hidromórficos em áreas mal drenadas (ambiente redutor) das planícies aluvionares, pode explicar a permanência deste radionuclídeo nestas regiões, sobre as quais cultiva-se a cana-de-açúcar. Entretanto, no estudo do ciclo de interações do tório, observou-se que a mobilidade do tório também pode ocorrer na forma de complexos e colóides, como nos casos de complexos solúveis de sulfatos, nitratos, carbonatos, fosfatos, silicatos, orgânicos, etc., que permitem ao tório certa solubilidade e mobilidade em condições naturais. 0 tório pode também ser transportado quando adsorvido em colóides argilosos e óxidos de ferro, podendo neste caso ser transportado das porções mais elevadas, onde ocorrem os Latossolos Roxos intensivamente fertilizados. Entretanto, Boyle (1982) citou que durante 0 desenvolvimento dos solos, quantidades consideráveis de urânio são lixiviadas pelo intemperismo, quando comparadas com 0 tório, aumentando, portanto, a razão Th/U em relação a rocha fonte. Se o urânio, de acordo com Boyle (1982), apresenta uma vulnerabilidade maior à lixiviação quando comparado ao tório, por que então 0 Th estaria naquelas porções onde se encontram os aluviões e não o U? Uma das hipóteses seria que 0 referido levantamento aerogeofísico detectou contribuição de eTh proveniente de fertilizantes fosfatados de origem ígnea nos solos sob cultura de cana-de-açúcar.

A Figura 11, uma síntese feita pelos autores para as variáveis espaciais, procura ilustrar a relação entre soleiras de diabásio, Latossolos Roxos e anomalias aerogamaespectrométricas investigadas na Quadrícula. Ao centro da referida Figura é apresentada a banda IVM do LANDSAT 5 TM. As classes sills de diabásio (do mapa geológico) e Latossolo Roxo (do mapa de solos) são mostrados no quadro (a) e (b), respectivamente. Observa-se a coincidência destas classes com relação ao elemento forma e nível de cinza na imagem de satélite. Pelo fato da cena ter sido obtida em época em que o solo estava descoberto (sem a cobertura da cultura de cana-de-açúcar), os tons de cinza mais escuros mostram claramente os solos derivados essencialmente das rochas básicas (Latossolos Roxos) em contraste às tonalidades mais claras onde situam-se os solos Podzólicos e Latossolos Vermelho Amarelo, com maior influência geológica da Formação Corumbataí e Aluviões do Quaternário, respectivamente. 0 quadro (c) mostra a classe referente às soleiras de diabásio, resultado da classificação não supervisionada da imagem de satélite, enfatizando a coincidência sill e Latossolo Roxo (b), oriundos de levantamentos de diferentes escalas e objetivos, mas com elevada correlação entre as variáveis. Aquelas poucas formas ou pequenos polígonos sobre a imagem, com distribuição fragmentada e tons de cinza mais escuros (valores digitais ou digital number ou DN's baixos), representam corpos d'água (lagos, represas), que pelo fato da banda pertencer a região do Infra-Vermelho-Médio, a água acaba por apresentar ausência de reflectância e 0 nível de cinza com valor de DN muito baixo (próximo de 15 quando na imagem bruta), sendo representado pela tonalidade mais escura. 0 rio Moji-Guaçu, em sua forma meândrica, corta a cena em sentido leste a noroeste mostrando às suas margens a textura mais lisa, DN's mais elevados, indicando a presença dos aluviões e conseqüentemente dos Latossolos Vermelhos Amarelos. Assim, em (d) é apresentada à coincidência de elevadas contagens de $\mathrm{Ke}$ eTh (classe oriunda da classificação não supervisionada da imagem gama KeUeTh) superposta à classe temática Qa (aluviões do Quaternário do mapa geológico). Observa-se que estas elevadas contagens de K e eTh, de fato se dão sobre os Latossolos VermeIhos Amarelos. A classe das elevadas contagens de K, eU e eTh, também oriundos desta a classificação é apresentada no quadro (e). Nota-se que as elevadas contagens das três variáveis não ocorrem nas porções do rio Moji-Guaçu. 0 quadro (f) mostra 0 resultado da tabulação cruzada entre o mapa contendo somente a classe sills de diabásio (a) e o mapa contendo somente a classe Latossolos Roxos (b). Em (f), a feição (ou classe) resultante do cruzamento destas (operação 〈AND〉). Finalmente, em (h), indicase 0 resultado do cruzamento entre elevadas contagens de $\mathrm{K}$, eU e eTh (e) e resultado do cruzamento de (g) (coincidência das classes sills de diabásio e Latossolo Roxo).

A Figura 12 mostra as imagens aerogamaespectrométricas do $\mathrm{K}$ (a), do eU (b) e do eTh (c) integradas ao relevo. As colorações verdes indicam elevados valores das variáveis geofísicas. Observa-se pelas Figuras 13b e 13c que nas porções mais elevadas e planas há predomínio de valores elevados de eU e eTh. São as áreas dos Latossolos Roxos, que são solos que 


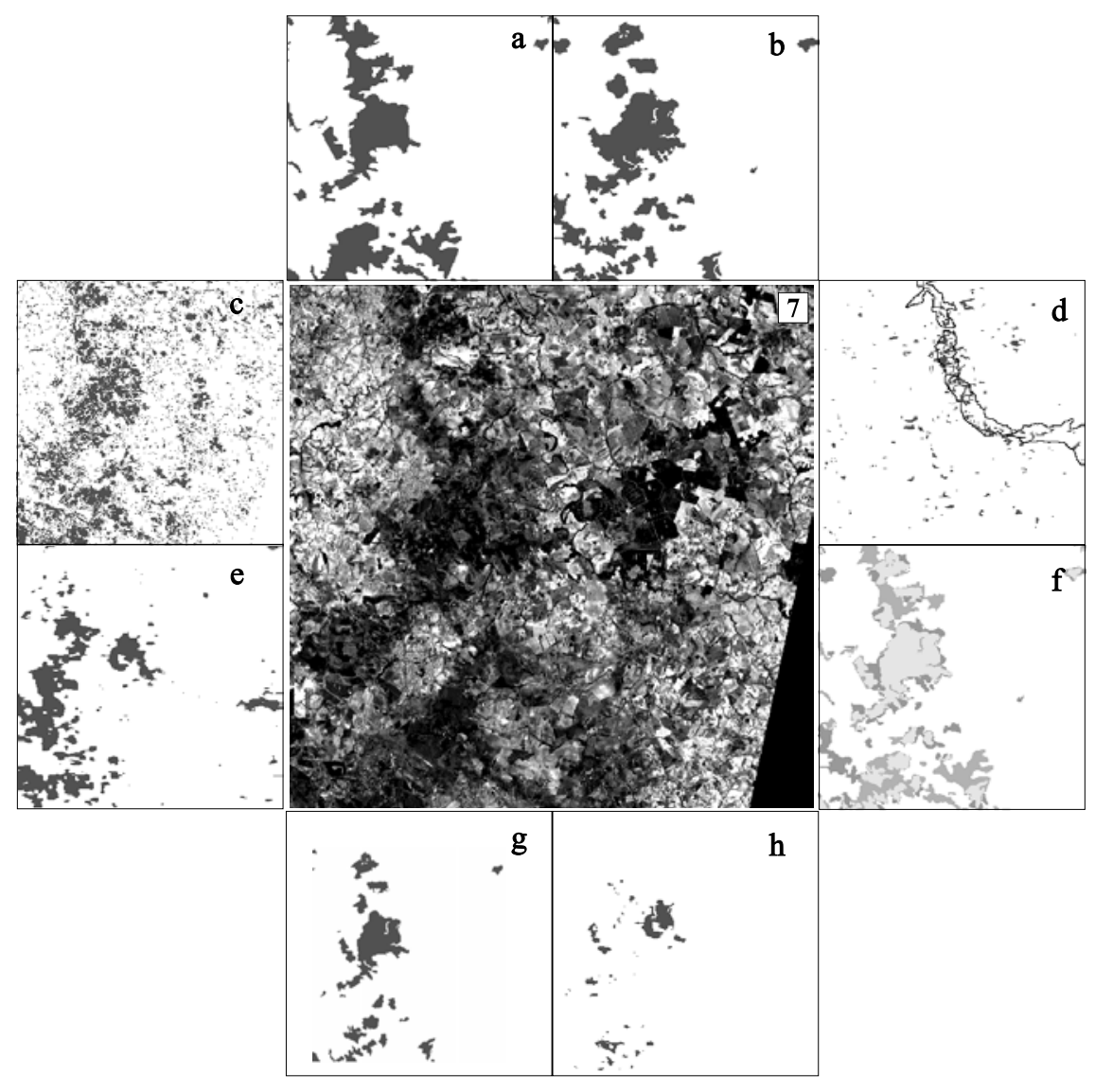

Figura 11 - Integração das variáveis espaciais.

ocorrem essencialmente sobre estes tipos de relevo. Na Figura 9a, observa-se o predomínio do K sobre a planície do Rio MojiGuaçu.

Um outro resultado que enfatiza a relação espacial de dados aerogamaespectroméricos às classes de solo Latossolo Roxo e Latossolos Vermelhos Amarelos, será mostrada a seguir pelo resultado de classificação dos dados aerogamaespctrométricos que seguiu os critérios de Nabi (1995) quando cruzado com o mapa de solos.

Os dados aerogamaespectrométricos originais de K, eU e eTh em cps, foram classificados de acordo com critérios de Nabi (1995). Para cada variável, obteve-se a média $(x)$ e 0 desvio padrão ( $s$ ), estabelecendo-se os fatores de significância, ou seja, os múltiplos do desvio padrão acima e abaixo da média. A Tabela 1 mostra os valores em contagens por segundo (cps) e a Figura 13 mostra o resultado da reclassificação.

As operações de multiplicação em SIG das classes de anomalias referentes a valores superiores a $x+3 s$ com as classes de solos, revelou que as ocorrências anômalas de urânio e de tório estavam predominando sobre os Latossolos Roxos.

Como os Latossolos Roxos identificados na área são derivados de processos maturos de intemperismo de rochas básicas, é provável que as anomalias de eU e eTh, sejam explicadas pelas seguintes razões: (i) menor mobilidade de $U$ e Th, quando comparados ao K; (ii) tendência destes radionuclídeos a serem rapidamente adsorvidos em minerais de argila e coprecipitados em óxidos de ferro nos solos, conforme Dickson \& Scott (1990 apud Wilford et al. 1997); (iii) concentração de U e Th na parte superior do perfil intemperizado devido a presença de argilas e/ou óxidos de ferro, como verificado por Koons (1980 apud Wilford et al. 1997) e Dickson \& Scott (1997). Entretanto, o urânio e o tório ali presentes também podem ser derivados da adição de fertilizantes fosfatados acrescidos ao comportamento destes elementos frente aos processos intempéricos, os quais culminam com o acúmulo natural de urânio e tório associados aos elevados teores de argilas e óxidos de ferro.

Assim, uma outra integração que reforça a hipótese de que 0 urânio ocorre preferencialmente em solos argilosos, é 0 cru- 

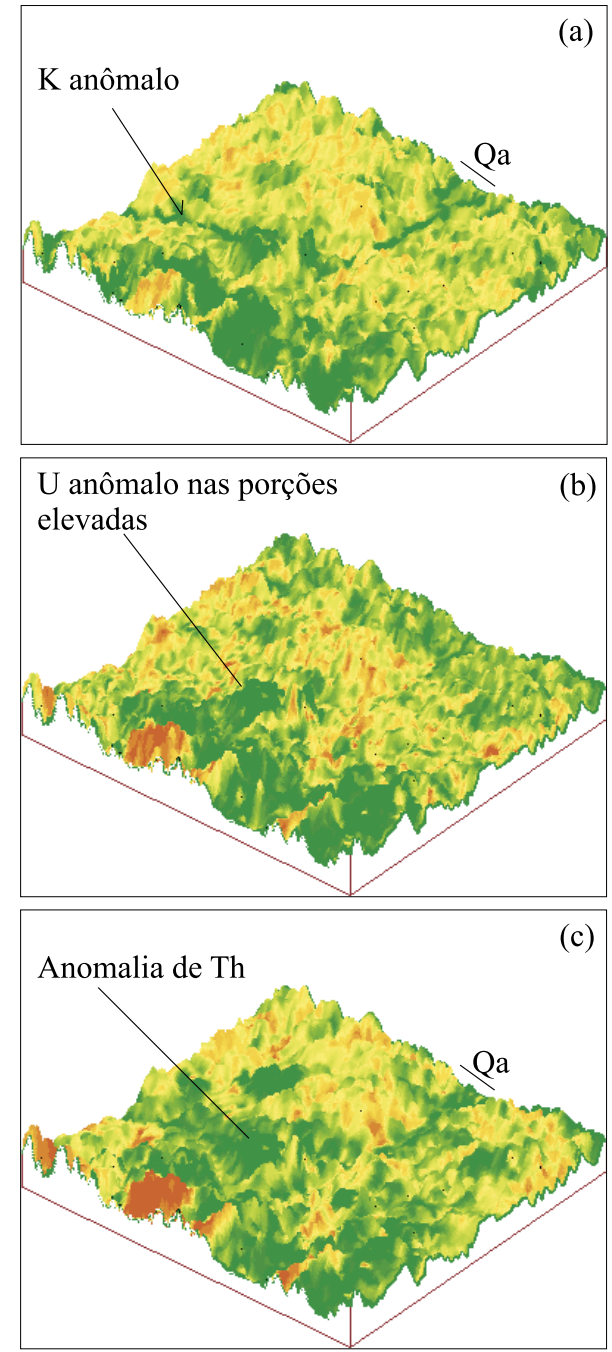

Figura 12 - Imagens aerogamaespectrométricas de K(a), eU(b) e eTh(c) integradas ao relevo.

Tabela 1 - Múltiplos da média (x) e do desvio padrão (s) de K(cps), eU(cps) e eTh(cps).

\begin{tabular}{|c|c|c|c|c|c|}
\hline Variável & Média $(\mathrm{x})$ & Desvio $(\mathrm{s})$ & $x+1 s$ & $x+2 s$ & $x+3 s$ \\
\hline Potássio (cps) & 25 & 17 & 42 & 59 & 76 \\
\hline Urânio (cps) & 17 & 8,5 & 25,5 & 34 & 42,5 \\
\hline Tório (cps) & 55 & 26 & 81 & 107 & 133 \\
\hline
\end{tabular}

zamento das suas informações geofísicas com as classes de formações superficiais tabuladas com a granulometria e a litologia. Na Figura 14 observa-se que a classe soleiras de diabásio, regolito, granulometria argila (Figura 14c) e a classe Formação Corumbataí, regolito granulometria argila (Figura 14d), são as que ocorrem nas regiões de elevados valores de urânio, representados por tons claros de cinza.

\section{Resultados radioquímicos}

Os resultados das análises radioquímicas são apresentados na Tabela 2.

\section{Amostras de Solos}

As amostras de solos referem-se às de indicação 800/96; 803/96; 804/96; 808/96; 811/96; 811/96 e 816/96. Observa-se que os 

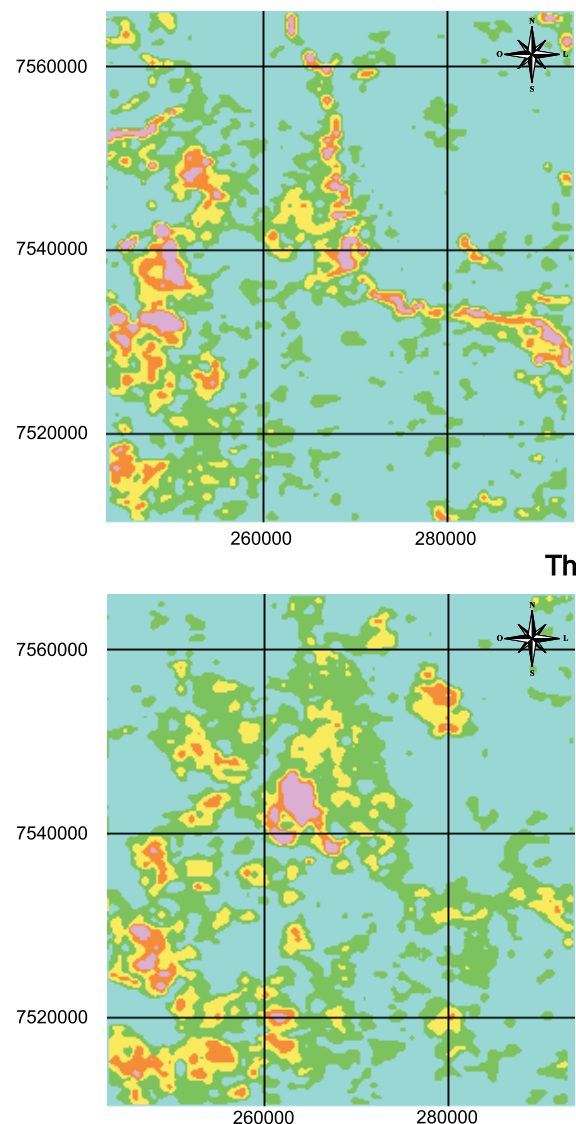

U
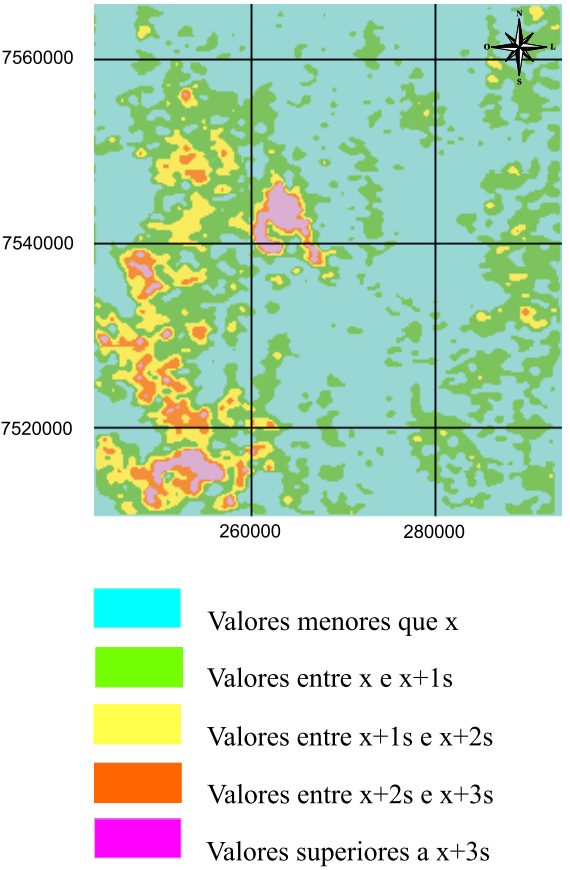

$\mathrm{x}=$ média; $\mathrm{s}=$ desvio padrão

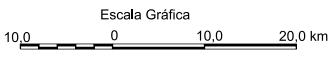

Figura 13 - Reclassificação das anomalias de K, eU e eTh.

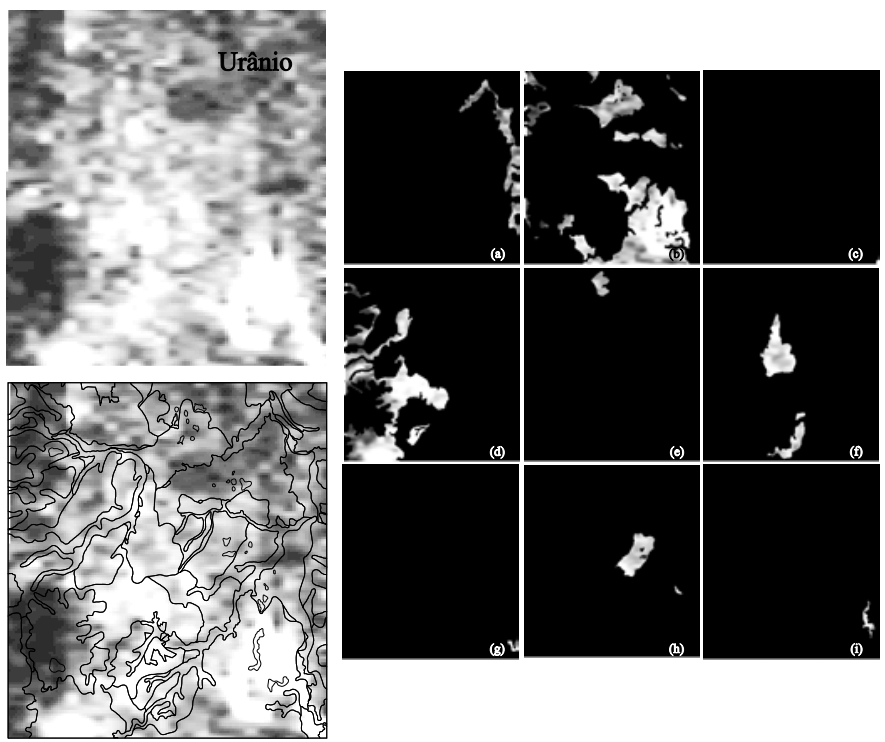

(a) Aluvião do quaternário, granulometria argila

(b) Soleiras diabásicas, regolito, granulometria argila;

(c) Soleiras diabásicas, regolito, granulometria silte e argila;

(d) Formação Corumbataí, regolito, granulometria argila;

(e) Formação Irati, regolito, granulometria silte e argila;

(f) Formação Irati, regolito, granulometria argila;

(g) Formação Tatuí, aluvião, granulometria silte argila;

(h) Formação Tatuí, regolito, granulometria argila;

(i) Formação Tatuí, regolito, granulometria silte e argila.

Figura 14 - Imagens de 8 bits de eU e litologias com granulometria argila e argila+silte da porção noroeste (Leme) da área de estudo. 
Tabela 2 - Resultados analíticos de urânio e tório de amostras de solos e fertilizantes da área de estudo.

\begin{tabular}{|c|c|c|c|c|c|}
\hline Amostra & $U_{\text {nat }}(\mathrm{ppm})$ & $\begin{array}{c}\mathrm{U}_{\text {nat }} \mathrm{Bq} / \mathrm{kg} \\
(\mathrm{sec})\end{array}$ & $\begin{array}{c}\mathrm{U}^{238} \mathrm{~Bq} / \mathrm{kg} \\
(\mathrm{sec} 0)\end{array}$ & $\begin{array}{c}\mathrm{Th}_{\text {nat }} \mathrm{Bq} / \mathrm{kg} \\
(\mathrm{sec} 0)\end{array}$ & $\mathrm{Th}_{\text {nat }}$ (ppm) \\
\hline $800 / 96$ & $7,58 \pm 0,23$ & $182,60 \pm 5,50$ & $94,05 \pm 2,80$ & - & - \\
\hline $803 / 96$ & $3,87 \pm 0,12$ & $93,08 \pm 2,81$ & $47,95 \pm 1,48$ & - & - \\
\hline $804 / 96$ & $11,56 \pm 0,49$ & $278,40 \pm 11,73$ & $143,40 \pm 6,05$ & $14,08 \pm 2,16$ & $3,46 \pm 0,53$ \\
\hline $808 / 96$ & $3,97 \pm 0,15$ & $95,70 \pm 0,35$ & $49,30 \pm 0,18$ & $21,36 \pm 2,12$ & $5,25 \pm 0,52$ \\
\hline $811 / 96$ & $8,0 \pm 0,29$ & $192,70 \pm 7,11$ & $99,26 \pm 3,66$ & - & - \\
\hline $816 / 96$ & $6,26 \pm 0,28$ & $150,70 \pm 6,83$ & $77,64 \pm 3,54$ & - & - \\
\hline FSS & $21,83 \pm 0,58$ & $533,92 \pm 14,13$ & $270,70 \pm 7,28$ & $402,52 \pm 12,70$ & $98,9 \pm 3,12$ \\
\hline $4-20-20$ & $18,53 \pm 0,63$ & $446,0 \pm 15,17$ & $229,80 \pm 7,81$ & $191,7 \pm 8,79$ & $47,1 \pm 2,16$ \\
\hline $4-14-08$ & $7,93 \pm 0,29$ & $190,9 \pm 7,13$ & $98,36 \pm 3,67$ & $622,71 \pm 49,25$ & $153,0 \pm 12,1$ \\
\hline
\end{tabular}

teores de urânio e tório são altamente variáveis. Podem ser considerados normais (1 a 8 ppm), ou seja, não são solos de áreas potencialmente uraníferas, os quais podem atingir valores de até 50 ppm. Contudo, Boyle (1982), cita que o teor médio de urânio em solos normais é de 1 ppm.

A Figura 15 mostra que apesar dos Latossolos Roxos serem solos exclusivamente derivados de rochas básicas, verifica-se que os teores encontrados de radioelementos nos solos amostrados foram superiores ao valor médio encontrado por Marques (1988) em derrames de rochas ácidas (derrame de riolito) e intermediárias (derrame de andesito). E, em maior grau ainda, a superioridade de U (ppm) foi verificada em relação às rochas básicas (derrames e sills de andesito basalto e basalto tholeiítico).

Os teores de tório só foram analisados para algumas amostras. Os valores mostraram-se bem baixos em relação aos teores indicados pela literatura (Boyle, 1982), de 0,1 a 50 ppm e teores médios de $5 \mathrm{ppm}$. Cabe ressaltar que na amostra de solo de maior profundidades $(40-60 \mathrm{~cm})$, 0 teor de urânio mostrou o maior valor $(11,56 \pm 0,49$ ppm). Os teores de urânio são mais elevados nas camadas do solo de maior concentração de argilas e/ou óxidos de ferro. Assim, quando comparados aos dados dos solos derivados de rochas extrusivas máficas (basalto) estudados por Dickson \& Scott (1997) onde encontraram U (ppm) em rocha e solo, respectivamente iguais a 0,3 a 1,3 e 0,6 a 2,5; Th (ppm) em rocha e solo respectivamente iguais a 2,0 a 5,0 e 3,3 a 13,0, os solos da presente pesquisa mostram um incremento de urânio bem maior em relação ao seu material de origem, refletindo assim a eventual possibilidade do incremento de radionuclídeos ( $U$ e Th), provenientes da adição de fertilizantes fosfatados, bem como 0 acúmulo natural de urânio e tório associados aos elevados teores de argilas e óxidos de ferro.

Comparação feita com os dados da média de U (ppm) obtidos por Rothbaum et al. (1979), em amostras de solos de diferentes áreas, onde $\mathrm{P}$ foi aplicado anualmente durante os anos de 1870-1880, 1940-1950 e 1976, mostra que os resultados radioquímicos do urânio das amostras de solos da presente pesquisa ainda são superiores nas camadas superficiais e subsuperficiais dos solos, mesmo contendo menores teores de matéria orgânica.

\section{Amostras de Fertilizantes}

Os resultados analíticos de amostras de fertilizantes (Tabela 2) referem-se a: FSS - superfosfato simples (ou SSP); 4-20-20 mistura NPK, com concentrações de $4 \%$ de N, $20 \%$ de $\mathrm{P}_{2} \mathrm{O}_{5} \mathrm{e}$ $20 \%$ de KCl; 4-14-08 - mistura NPK, com concentrações de 4\% de $\mathrm{N}, 14 \%$ de $\mathrm{P}_{2} \mathrm{O}_{5}$ e $8 \%$ de $\mathrm{KCl}$. Tais fertilizantes foram comprados na região, não representando necessariamente a mesma marca comercial mais utilizada na área de estudo.

0 resultado da análise do urânio na amostra de superfosfato simples revelou valores bem próximos ao encontrado por Pfister et al. (1976) também em amostras de SSP, de 21,51 ppm. Entretanto, valores de tório foram bem superiores ao encontrado por estes autores. Esta diferença pode ser atribuída a origem da matéria-prima ou rocha (Menzel, 1968) utilizada na fabricação deste fertilizante. Assim, provavelmente, a rocha usada para a fabricação do fertilizante analisado era de origem ígnea, uma vez que teores de tório mostraram-se bem superiores aos de urânio.

A influência da origem geológica da fonte de matéria-prima também foi observada na amostra 4-20-20 investigada. E consi- 


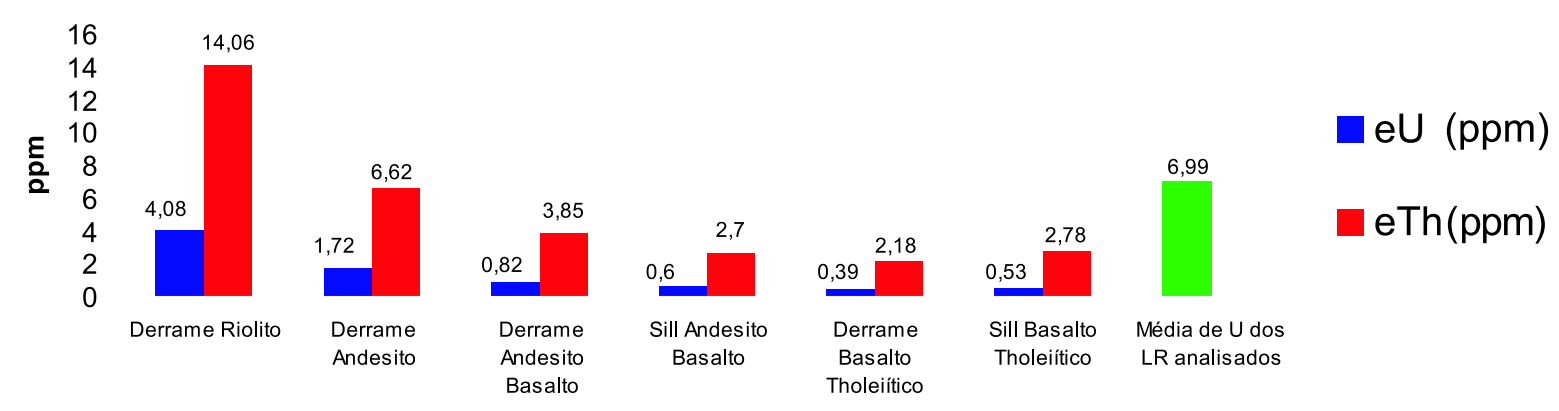

Figura 15 - Comparação entre as médias de U (ppm) em rochas vulcânicas da Bacia do Paraná (Marques, 1988) e a média de U (ppm) dos Latossolos Roxos da área de estudo.

derando que esta seja constituída de SSP + MAP, o que é mais provável e comum nos fertilizantes da região, os teores de urânio deveriam ser próximos ao do SSP analisado, uma vez que a concentração na fórmula de $\mathrm{P}_{2} \mathrm{O}_{5}$ é de $20 \%$ e na amostra de superfosfato varia entre 19 a $21 \%$. De fato, os resultados de $U_{\text {nat }}$ nos tipos SSP e NPK foram semelhantes $(21,83 \pm 0,58$ e $18,53 \pm 0,63$, respectivamente).

A fórmula 4-14-08 apesar de não ser utilizada na cultura da cana-de-açúcar, também foi analisada. Apresenta teor de $\mathrm{P}_{2} \mathrm{O}_{5}$ inferior ao dos outros fertilizantes analisados, confirmando-se assim que as concentrações de urânio crescem com os teores de $\mathrm{P}_{2} \mathrm{O}_{5}$ dos fertilizantes.

\section{Gamaespectrometria Terrestre e Susceptibilidade Magnética}

As medidas gamaespectrométricas terrestres e de susceptibilidade magnética $(\mathbf{k})$, realizadas em pontos espaçados de aproximadamente $1 \mathrm{~km}$, permitiram a montagem de cinco perfis (A-B, C-D, E-F, G-H, I-J), como mostrado na Figura 8. As médias obtidas pelas leituras das variáveis citadas, 0 tipo de cultura instalada, a geologia (IPT, 1993), os solos (Oliveira et al., 1981) e a granulometria (IG, 1980,1981,1987) dos pontos do perfil AB são mostradas na Tabela 3.

A gamaespectrometria terrestre $\left(\mathrm{K}\right.$, eU, eTh e $\left.\mathrm{TC}_{2}\right)$ e as medidas de susceptibilidade magnética realizadas no perfil A-B indicaram três unidades geológicas (Aluviões do Quaternário, Soleiras Diabásicas e Formação Piraçununga), bem como algumas classes de solos, como os Latossolos Roxos (LR), Latossolos Vermelhos-Escuros e Latossolos Vermelhos-Amarelos.

Os dados da Tabela 3, mostram as médias das variáveis geofísicas terrestres, o tipo de cultura instalada, as classes de solos, a geologia e a granulometria conforme a literatura mencionada. A média da susceptibilidade magnética do ponto 1 revelou ser este um solo de origem básica com contribuição de materiais do Quaternário, pois os dados geológicos do IG (1980) mostram que este ponto está inserido nos aluviões que margeiam o Ribeirão do Meio. Ao comparar esta média ( $\mathbf{k}=15,8$ ) com a média $(\mathbf{k}=35,06)$ dos solos de origem básica (Latossolos Roxos) referentes aos pontos 2,3,4,5,6,7,8,9, $12 \mathrm{e} 13$, sugere-se que a classe de solo do ponto 1, seja a do Latossolo Vermelho-Escuro (LE). Os pontos 10 e 11 não foram incluídos no cálculo da média de $\mathbf{k}$ dos LR, uma vez que apresentaram susceptibilidade baixa. Cabe ressaltar que dados de Oliveira et al. (1981), mostram que na unidade de mapeamento LRe podem ocorrer inclusões da unidade Limeira (LE-1). Souza (1998), através de análise de agrupamentos, utilizando-se de dados digitais fisiográficos e geofísicos da folha de Leme (SP), identificaram nesta região Latossolos VermelhosEscuros uma vez que tais solos encontram-se localizados nas porções mais baixas, associadas a redes de drenagem mais densas, relacionando-se a uma paisagem mais movimentada e dissecada, quando comparada àquela dos Latossolos Roxos. A Tabela 3 também revela certa diferença entre os dados gamaespectrométricos terrestres ( $\mathrm{K}$, eU, eTh e $\mathrm{TC}_{2}$ ) do ponto 1 e aqueles encontrados nos Latossolos Roxos (LR) anteriormente mencionados. 0 eU mostrou-se menor para 0 ponto 1 (1,0 cps), enquanto a média para os LR foi de 1,62 cps. A principal cultura realizada sobre os $L R$ deste perfil é a cana-de-açúcar, perfazendo cerca de $70 \%$ dos LR considerados. Ao comparar-se os dados gamaespectrométricos de um LR associado com cultura de algodão (ponto 6) com os dados do ponto 1 (também sob 0 mesmo cultivo), observa-se ainda que os dados médios de $\mathrm{U}$ e Th (eU = 1,6 cps; eTh = 0,9 cps) são superiores em relação ao LE do 
Tabela 3 - Dados do perfil AB.

\begin{tabular}{|c|c|c|c|c|c|c|c|c|c|c|c|c|}
\hline Ponto & \multicolumn{2}{|r|}{1} & 2 & 3 & 4 & 5 & \multicolumn{2}{|l|}{6} & 7 & 9 & 10 & 11 \\
\hline $\mathrm{Ct}_{2}$ (cps) $^{*}$ & \multicolumn{2}{|c|}{27,8} & 29,8 & 24,1 & 24,9 & 30,7 & \multicolumn{2}{|c|}{29,9} & 69,4 & 39,4 & 39,3 & 83,3 \\
\hline $\mathrm{K}(\mathrm{cps})^{*}$ & \multicolumn{2}{|c|}{1,8} & 1,5 & 1,3 & 1,3 & 1,6 & \multicolumn{2}{|l|}{1,4} & 3,9 & 2,2 & 2,1 & 3,9 \\
\hline $\mathrm{eU}(\mathrm{cps})^{*}$ & \multicolumn{2}{|c|}{1,0} & 0,8 & 0,9 & 0,7 & 0,9 & \multicolumn{2}{|l|}{1,4} & 2,0 & 2,5 & 2,1 & 3,2 \\
\hline eTh (cps) ${ }^{*}$ & \multicolumn{2}{|c|}{0,6} & 0,6 & 0,5 & 0,7 & 0,6 & \multicolumn{2}{|c|}{0,9} & 1,3 & 1,0 & 1,0 & 1,9 \\
\hline $\mathrm{k}\left(\times 10^{-3} \mathrm{SI}\right)$ & \multicolumn{2}{|c|}{15,8} & 45,9 & 20,6 & 29,2 & 29,3 & \multicolumn{2}{|c|}{47,0} & 65,7 & 27,5 & 0,9 & 8,6 \\
\hline $\begin{array}{l}\text { Geologia IG } \\
(1980,1987) \\
\end{array}$ & \multicolumn{2}{|c|}{$\mathrm{JK}_{\beta}(\mathrm{Qa})$} & $\mathrm{JK}_{\beta}$ & $\mathrm{JK}_{\beta}(\mathrm{Qa})$ & $\mathrm{JK}_{\beta}$ & $\mathrm{JK}_{\beta}$ & \multicolumn{2}{|c|}{$\mathrm{JK}_{\beta}$} & $\mathrm{JK}_{\beta}$ & $\mathrm{JK}_{\beta}$ & Qa & $\mathrm{JK}_{\beta}(\mathrm{Qa})$ \\
\hline $\begin{array}{c}\text { Form. Sup. } \\
(\mathrm{IG}, 1980,1987)\end{array}$ & \multicolumn{2}{|c|}{$\operatorname{Ar}(\mathrm{I})$} & $\mathrm{Ar}$ & $\operatorname{Ar}(I)$ & $\mathrm{Ar}$ & $\mathrm{Ar}$ & \multicolumn{2}{|l|}{$\mathrm{Ar}$} & $\mathrm{Ar}$ & $\mathrm{Ar}$ & 1 & $\operatorname{Ar}(\mathrm{I})$ \\
\hline $\begin{array}{c}\text { Solo } \\
\text { (Oliveira et al., } 1981\end{array}$ & \multicolumn{2}{|c|}{ LR } & LR & $\mathrm{LR}$ & $\mathrm{LR}$ & LR & \multicolumn{2}{|l|}{$\mathrm{LR}$} & $L R$ & $\mathrm{LR}$ & $L R$ & LR \\
\hline Cultura & \multicolumn{2}{|c|}{ Algodão } & Sorgo & Cana & Cana & Cana & \multicolumn{2}{|c|}{ Algodão } & Cana & Cana & Eucalipto & Algodão \\
\hline Ponto & \multicolumn{2}{|l|}{12} & 14 & 15 & 16 & 17 & 18 & 19 & 20 & 21 & 22 & 23 \\
\hline $\mathrm{Ct}_{2}(\mathrm{cps})^{*}$ & 62,4 & 42,2 & 25,8 & 41,2 & 52,3 & 36,9 & 36,3 & 32,8 & 22,9 & 29,7 & 30,2 & 31,7 \\
\hline $\mathrm{K}(\mathrm{cps})^{*}$ & 2,5 & 2,1 & 1,4 & 1,9 & 3,5 & 2,4 & 1,7 & 2,1 & 1,2 & 1,9 & 1,6 & 2,1 \\
\hline eU (cps)* & 2,3 & 1,8 & 1,1 & 1,6 & 1,7 & 1,4 & 1,5 & 1,4 & 0,8 & 1,1 & 1,2 & 1,3 \\
\hline eTh $(c p s)^{*}$ & 1,4 & 0,8 & 0,5 & 0,9 & 1,3 & 0,8 & 0,9 & 0,8 & 0,6 & 0,6 & 0,5 & 1,0 \\
\hline $\mathrm{k}\left(\times 10^{-3} \mathrm{SI}\right)$ & 23,4 & 33,4 & 3,4 & 1,6 & 0,4 & 0,6 & 0,6 & 0,2 & 0,8 & 0,8 & 2,0 & 2,3 \\
\hline $\begin{array}{l}\text { Geologia IG } \\
(1980,1987) \\
\end{array}$ & $\mathrm{JK}_{\beta}$ & $\mathrm{JK}_{\beta}$ & Qa & $\mathrm{Qa}$ & $\mathrm{Qa}$ & $\mathrm{Qa}$ & $\mathrm{Qa}$ & Qa & $\mathrm{Tp}(\mathrm{Qa})$ & $\mathrm{Tp}(\mathrm{Qa})$ & $\mathrm{Tp}$ & Tp \\
\hline $\begin{array}{c}\text { Form. Sup. } \\
(\mathrm{IG}, 1980,1987)\end{array}$ & $\mathrm{Ar}$ & $\mathrm{Ar}$ & $\mathrm{Ar}$ & $\mathrm{Ar}$ & I & I & a & A & A & A & $\mathrm{AAr}$ & A \\
\hline $\begin{array}{c}\text { Solo } \\
\text { (Oliveira et al., } \\
1981)\end{array}$ & LR & $L R$ & PV4 & $\begin{array}{c}\mathrm{LV} 6+ \\
\mathrm{CB} 2+ \\
\mathrm{Hi}\end{array}$ & $\begin{array}{c}\text { LV6+ } \\
\mathrm{Cb} 2+ \\
\mathrm{Hi}\end{array}$ & $\begin{array}{c}\mathrm{LV} 6+ \\
\mathrm{Cb} 2+ \\
\mathrm{Hi}\end{array}$ & $\begin{array}{c}\mathrm{LV} 6+ \\
\mathrm{Cb} 2+ \\
\mathrm{Hi}\end{array}$ & $\begin{array}{c}\text { LV6+ } \\
\text { Cb2+ } \\
\mathrm{Hi}\end{array}$ & LV5 & LV5 & LV5 & LV5 \\
\hline Cultura & Citrus & Cana & Milho & Cana & Cana & Cana & Cana & Cana & Citrus & Citrus & Citrus & Sem cultura \\
\hline
\end{tabular}

*gamaespectrometria terrestre

ponto 1. Os dados médios de $K$ são maiores que 0 LR do ponto 6 , entretanto próximos aos dos $L R$ acima considerados $(K=1,95)$, com exceção do ponto $8(K=3,9)$.

Os solos inseridos nos aluviões do Quaternário (pontos 15, 16, 17, 18 e 19) apresentaram média de $\mathbf{k}(0,68)$ bem inferior aos solos de origem ou com contribuição básica. Estes solos, considerados por Oliveira et al. (1981) como uma associação de solos (LV-6+Cb-2+Hi), estão sob o cultivo de cana-de-açúcar. Ao comparar-se a média dos radioelementos com as correspondentes dos Latossolos Roxos, verifica-se que estes solos aluviais apresentam média de eU e eTh (1,55 e 0,95 cps, respectivamente) próximas às encontradas nos solos das soleiras (1,62 e 0,90cps). Entretanto, a média de K mostrou-se superior (2,34 cps) nos solos aluviais, em função da presença de feldspatos potássicos e micas nos minerais formadores destes solos, bem como pelo potássio lixiviado das porções mais elevadas do terreno, ou ainda o possível despejo de vinhaça sobre as margens do rio MojiGuaçu.

Com base na integração das informações de gamaespectrometria terrestre, de susceptibilidade magnética, de geologia, de solos e de granulometria, pode-se propor para o perfil A-B que os pontos $1 \mathrm{e} 3$ referem-se a Latossolos Vermelhos-Escuros. Este último ponto, apesar ter sido considerado um Latossolo Roxo no cálculo da média, é provável que seja um Latossolo VermelhoEscuro, uma vez que apresenta susceptibilidade magnética média $(\mathbf{k}=20,6)$ inferior aos solos de origem básica e se encontram geologicamente em posição de transição entre soleiras de diabásio e aluviões. Situa-se em paisagem semelhante à verificada no ponto 1, sendo possivelmente incluído na classe Latossolo VermelhoEscuro identificado por Souza (1998). 


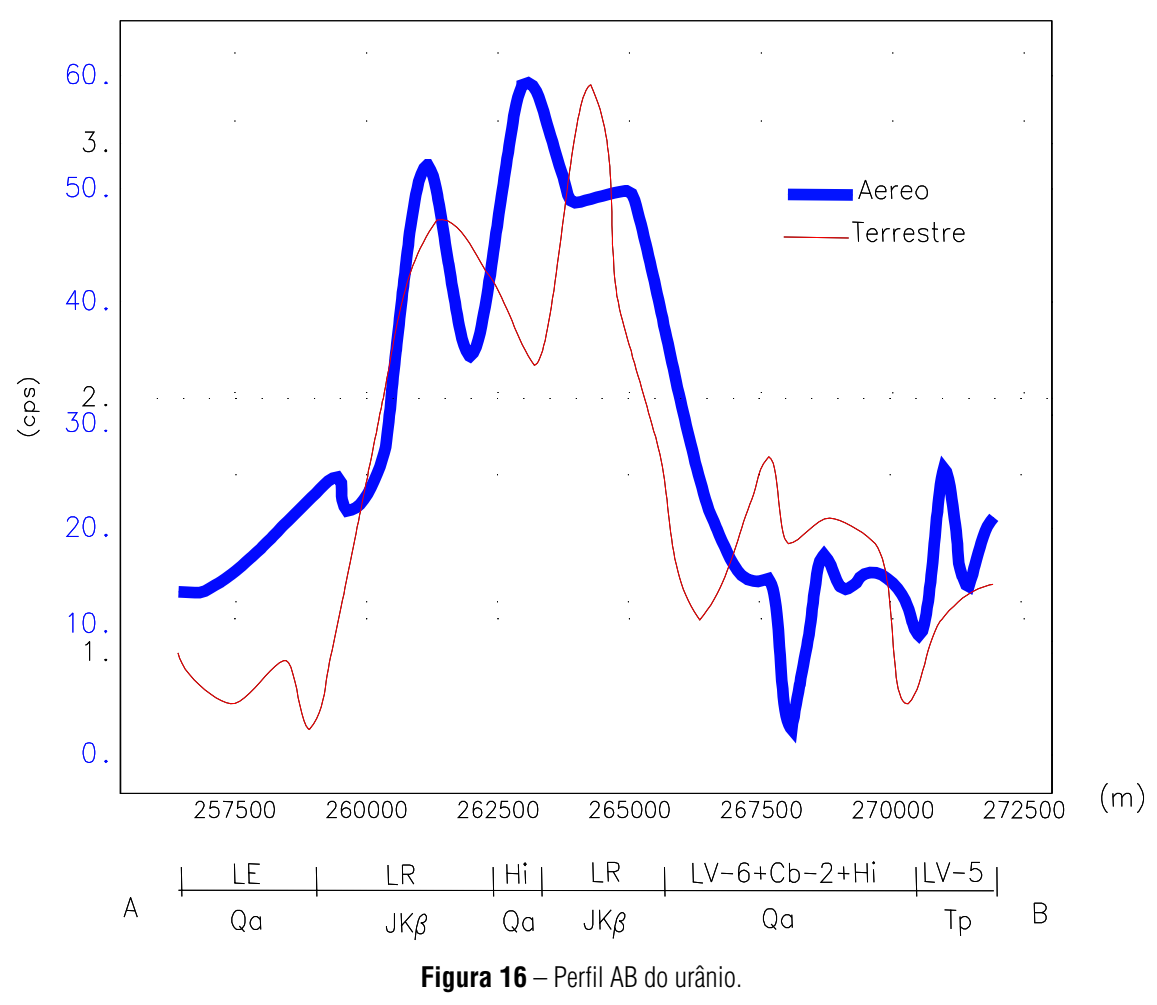

Observa-se também na Tabela 3, que no compartimento referente aos pontos 8, 9, 10,11, 12 e 13, existe uma tendência aos maiores valores dos dados gamaespectrométricos. Estes pontos estão inseridos nas anomalias de $U(>x+3 s)$, reforçando a hipótese do uso de fertilizantes fosfatados.

A consistência dos dados gamaespectrométricos terrestres de $\mathrm{Ct}, \mathrm{K}$, eU e eTh pôde ser verificada quando comparou-se o perfil A-B terrestre com os dados digitais aerogamaespectrométricos correspondentes. A partir do perfil terrestre, extraiu-se do arquivo digital aéreo um perfil passando pelos mesmos pontos. Obtevese assim um arquivo . $x y z$ para cada variável geofísica aérea, 0 qual foi integrado aos dados de superfície, como pode se observar na Figura 16. 0 mesmo procedimento foi aplicado aos outros perfis. No eixo $x$ do gráfico encontra-se a coordenada plana ( $x$ em metros no sistema UTM) dos pontos investigados. 0 eixo y mostra os valores em cps correspondentes aos pontos. Observa-se na referida figura uma boa correlação entre os dados terrestres e aéreos. Entretanto, quantitativamente, para todas as variáveis, existe uma grande diferença, decorrente da falta de calibração dos gamaespectrômetros, implicando em maiores contagens do sensor aéreo em função de seu maior volume, dificultando a correlaçãa entre dados aéreos e terrestres como discutido por Darnley \& Fleet (1968).

\section{CONCLUSÕES}

A integração dos dados multifonte revelou que: (i) as anomalias de eU e eTh ocorrem sobre os LR massivamente fertilizados com fosfatos, nas porções planas e elevadas do terreno; (ii) os níveis de eU estão associados à granulometria argila em regolitos desenvolvidos sobre soleiras de diabásio; (iii) anomalias de $\mathrm{K} \mathrm{e}$ eTh acompanham os aluviões do Quaternário das margens do rio Moji-Guaçu, atribuindo-se às ocorrências de $\mathrm{K}$ anômalo como derivadas de feldspatos potássicos e da contribuição dos fertilizantes utilizados e a ocorrência de eTh associada à fertilização local e ao transporte de óxidos de ferro e argilas provenientes das porções mais elevadas do terreno, onde situam-se os LR sob cultivo de cana-de-açúcar, bem como a retenção deste radionuclídeo pela matéria orgânica nos aluviões.

As análises radioquímicas dos solos e fertilizantes revelaram a ocorrência de U e Th. Urânio nos solos amostrados exibem concentrações superiores aos teores médios indicados pela literatura em solos ditos normais, e superiores aos obtidos em pesquisa sobre a acumulação deste radionuclídeo em solos fertilizados há mais de 80 anos. Observou-se também a influência da origem geológica da fonte de matéria-prima utilizada para a fabricação do fertilizante. 
As medidas gamaespectrométricas terrestres mostraram boas relações com as detecções aerogamaespectrométricas. Dados de susceptibilidade magnética (k) mostraram que urânio e tório tendem a se concentrar em solos mais desenvolvidos, argilosos e com $\mathbf{k}$ elevados. Tais características possibilitam a fixação destes radionuclídeos provenientes dos fertilizantes fosfatados.

A retenção de eU e eTh em solos mais desenvolvidos e com predominância de argilas e óxidos de ferro, aliada a informações de topografia, denotaram contagens gamaespectrométricas maiores do que as encontradas em pedreira de diabásio (rocha sã com baixos eU e eTh).

Os maiores valores de $\mathrm{K}$ foram encontrados nos solos aluvionares devido a presença de feldspatos e micas oriundos dos sedimentos da Bacia do Paraná e dos tratos mais elevados do embasamento cristalino, somados a utilização de fertilizantes potássicos (KCl e vinhaça) no cultivo de cana-de-açúcar.

\section{AGRADECIMENTOS}

Os autores agradecem ao Instituto de Engenharia Nuclear (IEN), da Comissão Nacional de Energia Nuclear (CNEN), pela realização das análises radioquímicas de solos e fertilizantes e à Comissão de Aperfeiçoamento de Pessoal de Nível Superior - CAPES pelo incentivo na forma de bolsa de mestrado.

\section{REFERÊNCIAS}

AGUIRRE AM, LÉON MG \& IVANOVICH M. 1995. U and Th speciation in river sediments. The Science of the Total Environment, 173-174: 203209

AMARAL RS, VASCONCELOS WE, BORGES E, SILVEIRA SV \& MAZZILLI BP. 2005. Intake of uranium and radium-226 due to food crops consumption in the phosphate region of Pernambuco - Brazil. Journal of Environmental Radioativity, 82: 383-393.

ANJOS ILS \& MOURÃO LMF. 1988. Projeto São Paulo - Rio de Janeiro, Relatório Final, Processamento de Dados, Parte I-São Paulo. Texto, v.2, Companhia de Recursos Minerais - CPRM, $29 \mathrm{p}$.

BOYLE RW. 1982. Geochemical prospecting for thorium and uranium deposits. Developments in economic geology, n.16, p. 71-78.

BRIGGS IC. 1974. Machine contouring using minimum-curvature. Geophysics, 39: 39-48.

BROLLO JM. 1991. Mapeamento geotécnico da quadrícula de ArarasSP, escala 1:50.000. São Carlos, Dissertação de Mestrado, Curso de Pós-Graduação em Engenharia. Escola de Engenharia de São Carlos, Universidade de São Paulo, 88 p.

DARNLEY AG \& FLEET M. 1968. Evaluation of airborne gamma-ray spectrometry in the Bancroft and Elliot Lake areas of Ontario, Canada. Proc.
In: 5th SYMPOSIUM ON REMOTE SENSING OF ENVIRONMENT. University of Michigan, Ann Arbor, p. 833-853.

DICKSON BL \& SCOTT KM. 1997. Interpretation of aerial gamma-ray surveys - adding the geochemical factors. AGSO Journal of Australian Geology \& Geophysics, Australia, 17(2): 187-200.

FERREIRA FJF. 1991. Aerogamaespectrometria e aeromagnetometria de um trato ocidental do Pré-Cambriano paulista. Tese de Doutoramento, Programa de Pós-graduação em Geoquímica e Geotectônica, Instituto de Geociências, Universidade de São Paulo, 150 p.

FERREIRA FJF, SOUZA JL, ROCHA HO \& MANTOVANI LE. 1997. Airborne gamma-ray spectrometry and remote sensing to map uranium accumulation in soils from long continued application of fertilizers in Araras region, Brazil. In: $12^{\text {th }}$ International Conference and Workshops, Applied Geologic Remote Sensing, Denver, Colorado, USA. V.I, p.323-330.

FERREIRA FJF \& SOUZA JL. 1999. Radioatividade anômala em solos: intemperismo ou fertilizantes fosfatados? In: XII Congreso LatinoAmericano de la Ciencia del Suelo, Pucón, Temuco, Chile, Universidad de la Frontera, p. 43.

FREITAS RO, MEZZALIRA S, ODA GH, VIEIRA PC, TORRES CC, HACHIRO J, TOMONAGA LK, DEHIRA LK, MASSOLI M, AZEVEDO AAB \& PRESSINOTI MMN. 1979. Projeto Levantamento Geológico de Formações Superficiais. In: Simpósio Regional de Geologia, II; Rio Claro. Atas..., v.2, SBG, Núcleo São Paulo, p. 263-277.

GRASTY RL, KOSANKET KL \& FOOTES RS. 1979. Fields of view of airborne gamma-ray detectors. Geophysics. 44(8): 1447-1457.

GUIMOND RJ \& HARDIN JM. 1989. Radioactivity released from phosphatepcontaining fertilizers and from gypsum. J. Radiat. Appl. Instrum. Radiat. Phys. Chem., 34(2): 369-315.

GUZMAN ETR, RÍOS MS, GARCÍA JLI \& REGIL E0. 1995. Uranium in phophate rock and derivatives. Journal of radioanalytical and nuclear chemistry. 189(2): 301-306.

IBGE. INSTITUTO BRASILEIRO DE GEOGRAFIA E ESTATÍSTICA. 1969. Carta topográfica da folha de Araras (SP). Rio de Janeiro: Fundação IBGE. 1 mapa. Escala 1:50.000.

IBGE. INSTITUTO BRASILEIRO DE GEOGRAFIA E ESTATÍSTICA. 1971a. Carta topográfica da folha de Leme (SP). Rio de Janeiro: Fundação IBGE. 1 mapa. Escala 1:50.000.

IBGE. INSTITUTO BRASILEIRO DE GEOGRAFIA E ESTATÍSTICA. 1971b. Carta topográfica da folha de Rio Capetinga (SP). Rio de Janeiro: Fundação IBGE. 1 mapa. Escala 1:50.000.

IBGE. INSTITUTO BRASILEIRO DE GEOGRAFIA E ESTATÍSTICA. 1974. Carta topográfica da folha de Conchal (SP). Rio de Janeiro: Fundação IBGE. 1 mapa. Escala 1:50.000.

IG. INSTITUTO GEOLÓGICO. 1980. Formações superficiais - Folha geológica de Leme. São Paulo: Aerofoto Cruzeiro S.A. 1 mapa: color. Escala 1:50.000. 
IG. INSTITUTO GEOLÓGICO. 1981. Formações geológicas de superfície - Folha geológica de Rio Capetinga. São Paulo: Aerofoto Cruzeiro S.A. 1 mapa: color. Escala 1:50.000.

IG. INSTITUTO GEOLÓGICO. 1987. Formações superficiais - Folha geológica de Araras. São Paulo: Aerofoto Cruzeiro S.A. 1 mapa: color. Escala 1:50.000.

IPT. INSTITUTO DE PESQUISAS TECNOLÓGICAS DO ESTADO DE SÃO PAULO. 1993. Mapa geológico da folha de Campinas. São Paulo: DIGE0. 1 mapa: cópia heliográfica. Escala 1:250.000.

KHAN K, KHAN HM, TUFAIL M, KHATIBEH AJAH \& AHMAD N. 1998. Radiometric Analysis of Hazara Phosphate Rock and Fertilizers in Pakistan. J. of Environ. Radioactivity, 38(1): 77-84.

MAZZILLI B, PALMIRO V, SAUEIA C \& NISTI MB. 2000. Radiochemical characterization of Brazilian phosphogypsum. Journal of Environmental Radioactivity, 49: 113-122.

MENZEL RG. 1968. Uranium, radium and thorium content in phosphate rocks and their possible radiation hazard. Journal of Agriculture Food Chemistry., 16: 231-284.

MARQUES LS. 1988. Rare elements. In: PICCIRILO EM \& MELFI AJ. The Mesozoic flood volcanism of the Paraná Basin. São Paulo: Universidade de São Paulo, Instituto Astronômico e Geofísico. p. 499-504.

MILANI EJ. 1997. Evolução tectono-estratigráfica da Bacia do Paraná e seu relacionamento com a geodinâmica fanerozóica do Gondwana sulocidental. Porto Alegre, Instituto de Geociências, Universidade Federal do Rio Grande do Sul, Tese de Doutoramento, 255 p.

MILANI EJ \& RAMOS VA. 1998. Orogenias paleozóicas no domínio sulocidental do Gondwana e os ciclos de subsidência da Bacia do Paraná Rev. Bras. Geoc. 28(4): 527-544.

MORTVEDT JJ. 1986. Effects of calcium silicate slag application on radium-226 concentrations in plant tissues. Commun. in Soil Sci. Plant Anal., 17: 75-84.

NABI SHAE. 1995. Statistical evaluation of airborne gamma-ray spectrometric data from the Magal Gebriel area, south Eastern Desert, Egypt. Journal of Applied Geophysics, 34:47:54.

NUERNBERG NJ, RECH TD \& BASSO C. 2002. Usos do gesso agrícola. Florianópolis, Epagri, Boletim Técnico 122, 31 p.

OLIVEIRA JB, MENK JRF, BARBIERI JL, ROTTA CL \& TREMOCOLDI W. 1981. Mapa do levantamento pedológico semi-detalhado do Estado de São Paulo - Quadrícula Araras. Campinas: Aerofoto Cruzeiro S.A. 1 mapa: color. Escala 1:100.000.

PASCHOA AS, MAFRA OY, CARDOSO DO \& ROCHA ACS. 1984. Application of SSNTD to the Brazilian phosphate fertilizer industry to determine uranium concentrations. Nuclear Tracks and Radiation Measurements, 8(1-4): 469-472.
PFISTER H, PHILIPP G \& PAULY H. 1976. Population dose from natural radionuclides in phosphate fertilizers. Radiation and Environmental Biophysics, 13: 247-261.

RING RJ. 1977. Recovery of by product uranium from the manufacture of fosfatic fertilizers. Atomic Energy, p. 12-20.

ROTHBAUM HP, McGAVESTON DA, WALL T, JOHNSTON AE \& MATTINGLY GEG. 1979. Uranium accumulation in soils from long-continued applications of superphosphate. Journal of Soil Science, march. Oxford, 30(1): 147-153.

SAN MIGUEL, PÉREZ-MORENO JP, BOLIVAR JP \& GARCÍA-TENÓRIO R. 2003. Validation of isotope signatures in sediments affected by anthropogenic inputs from uranium series radionuclides. Environmental Pollution, 123: 125-130.

SAUEIA CH, MAZZILLI BP \& FÁVARO DIT. 2004. Natural radioactivity in phosphate rock, phosphogypsum and phosphate fertilizers in Brazil. Journal of Radioanalytical and Nuclear Chemistry, 264(2): 445-448

SAUNDERS DF \& POTTS MJ. 1976. Interpretation and application of high-sensitivity airborne gamma-ray spectometer data. In: Exploration for uranium ore deposits. Proc Series. Vienna, Austria: IAEA. p. 107125.

SPALDING RF \& EXNER ME. 1976. Temporal uranium variations in the Brazos river. Radioecology and Energy Resources, p. 230-233.

SOUZA JL, FERREIRA FJF, ROCHA HO \& MANTOVANI LE. 1997. Soil radioactivity and its possible relationship in Araras region, Brazil. In: $4^{\text {th }}$ Meeting on Nuclear Applications. Poços de Caldas-MG, Edição em CD ROM, CNEN.

SOUZA JL. 1998. Anomalias aerogamaespectrométricas (K, U e Th) da Quadrícula de Araras (SP) e suas relações com processos pedogenéticos e fertilizantes fosfatados. Curitiba, Dissertação de Mestrado, Curso de Pós-Graduação em Geologia Ambiental, Universidade Federal do Paraná, $218 p$

SOUZA JL, ROCHA HO, FERREIRA FJF \& MANTOVANI LE. 1996. Anomalias aerogamaespectrométricas (K, U e Th) da região de Leme (SP) e suas relações com atividades agrícolas. In: Congresso Brasileiro de Geologia, XXXIX; Salvador. Anais... Salvador: SBG, 1996, p. 47-50.

WILFORD JR, BIERWIRTH PN \& CRAIG MA. 1997. Application of gamma-ray spectrometry in soil/regolith mapping and geomorphology. AGSO Journal of Australian Geology \& Geophysics, 17(2): 201-216.

YAMAZAKI IM \& GERALDO LP. 2003. Uranium content in phosphate fertilizers commercially produced in Brazil. Applied Radiation and Isotopes., 59: 133-136.

ZIELINSKI RA, BOLINDER SA, MÉIER AL, JONHSON CA \& SZABO BJ. 1997. Natural or fertilizer-derived uranium in irrigation drainage: a case study in southeastern Colorado, USA. Applied Geochemistry, 12: 9-21. 


\section{NOTAS SOBRE OS AUTORES}

Jocelyn Lopes de Souza é Engenheira Agrônoma (UEPG, 1992), Mestre em Geologia Ambiental (UFPR, 1998). Coordenadora do Laboratório de Geoprocessamento (LABGEO - Curso de Geografia) da Universidade Tuiuti do Paraná - UTP, sendo professora desde 1999 de disciplinas de geoprocessamento e análise geográfica, processamento digital de imagens, pedologia aplicada. No Centro Universitário Campos Andrade (Curitiba - PR) é professora de Sistemas de Informaç̧ões Geográficas e Sensoriamento Remoto, Fundamentos de Cartografia. Atua em geofísica aplicada (gamaespectrometria e solos); meio ambiente e levantamento do meio físico para elaboração de atlas municipais.

Francisco José Fonseca Ferreira é Geólogo (UFPE, 1970), Especialista em Geofísica Aplicada (UFBA, 1974), Mestre e Doutor em Ciências (USP, 1982; USP, 1991), tendo desenvolvido suas atividades profissionais na CPRM (1972-1980) e no IPT (1981-1990). Desde 1992 é Professor Adjunto do Departamento de Geologia da UFPR, onde ministra disciplinas de geofísica aplicada na graduação e na pós-graduação. A partir de 1998 é Coordenador do Laboratório de Pesquisas em Geofísica Aplicada (LPGA), onde desenvolve pesquisas em geofísica aplicada à cartografia geológica, exploração mineral, águas subterrâneas e meio ambiente. 